\title{
La Universidad de San Cristóbal de Ayacucho y sus Constituciones
}

La Universidad de "San Cristóbal de Ayacucho", iué fundada el 3 de jutio do 1677. por el ilustre Obispo Doctor Don Cristóbal Castilla y Zamora, aprobada por Real Cédula dol Rey Carlos Il el 31 de diciembre de 1680, y confirmada por su Santidad Inocencio XI. el 20 de diciembre de 1682. Este Prelado, para tal !in, donó de su propio peculio 70,000 pesos, y obtuvo los mismos privilegios y regalías que las Universidades de Lima, México y Salamanca. (1)

Fundada la Universidad, no pudo funcionar duranta más de 20 años, debido a una serie de causas, que no es del caso enunciar. La Universidad de San Marcos, forjadora de la cultura peruana, con su centralismo exacerbante, se opuso a su fundación (2). Dos macizos memoriales presentados al Gobierno, firmados por el Claustro en pleno, son el saldo de la oposición. El Doctor Diego Ladrón de Guevara, a la sazón obispo de Ayacucho, en una fundamentada carta de fecha 3 de marzo de 1701, se dirige al Virrey, so. licitando el PASE de la Universidad fundada, manifestando "la gran falta que hacen en Gllas rnás Escuelas en que se enseñen las facultades mayores y se instruyan los sujetos que se dedican a la Yglesia" y agrega que sus Gentas exiguas se habían aumentado considerablemente. Influye también en esta empresa eh fundador Castilla y Zamora, que había sido trasladado al arzobispado de Charcas (3).

El alegato San Marcos-San Cristóbal, si así podríamos llamar, duró como tres años, pero el 13 de setiembre de 1703, el Virrey Conde de Monclova (4), dió oído a las insistentes gestiones, y culmina con la otorgación del PASE expresando: "mando corra la fundación de la Real Universidad de la Ciudad de Guamanga en conformidad de la fa cultad que le está concedida". El 28 de febrero de 1704, se celebró la primera sesión del Claustro Universitario, para luego funcionar ininterrumpidamente hasta la dación del Reglamento de Instrucción Pública de 1876, (18 de marzo) por el que se clausuraron las Universidades de Puno, Trujillo y Ayacucho (5). Cerrándose definitivamente la primera, reabriéndose la segunda el 29 de abril de 1894, en virtud de la ley de 27 de octubre de 1891, que había ordenado su reorganización, y la tercera se rehabilita nuevamente el 13 de enero de 1884, para después ser clausurada definitivamente por Ley de 25 de octubre de 1886, dado por el entonces Presidente de la República Don Andrés Avelino Cáceres, sin poder restablecerse hasta hoy.

Cerca de 200 años de vida tuvo la Universidad de San Cristóbal. Desde el primer Rector que fué el chantre de la Iglesia Catedral el Doctor Gaspar Ortiz Espinoza (6) hasta el último el Doctor Marcelino Cleto Sáez, la Universidad forjó un sinnúmero de profesionales de todas partes, que dieron prestigio al "Alma Mater". 
Los primeros años de su vida universtarix, ge distingue, porque a su seno so incorporaron (7) una pléyade de doclores do las Unversidates existentes entonces y del exiranjero: slendo el primero ol Docler Francisco Garcia do Loaiza Dcin de la Catedral de Ayacucho, graduado de Doctor en la Universidad de Lima, quicn so incorpors llenando todos los requisitos pereristos y con tocia solemnidad dei caso, ol 21 de enero do 1704. Do la misma manera lo hacen, abogados de la fieal A.uciencia de Lima, como Don Padro Homani y Carrillo en febrero de 1704; igualmente los graduaclos de la Univergidad del Cuzco: el Br. Don Isidzo Cárdenas en marzo del mixno año: on la mismá fecha se incor. pora el Er. en Antes y Br. en Sagrada Teologí de la Universiddad de Lima Josó de Llano Astorga. Simulláneamente atraidos quizj por el clima frimaveral y los deseos de cono. cer otros centros de cultura, estudianles de otras universidades se trásladan a San Criatóbal; tal por ejemplo tl caso de Fray Francisco Anda Maldonado, comendador del Convento da Nuestra Señora de las Mercedes de Huamanga. que siendo seglar se graduó do Maestro en Artes en la ciudad de Quilo. lué Regente de Estudios de la Universidad de Chuquisaca; el caso de Don Manuel de Romani y Carrillo, eura y vicario de Lircay (Huancavelica: que estudió tres afios de A.rtes y cuatro de Teologia on el Cologio do San Martín de Lima. Amibos solicilan grados de $\mathrm{Br}$. en Artes, Br. en Teología, Licensiado on Teología y Doctor en Teologia, que le son concedidos en abril de 1704. Y asi, una comente admirable de doctores se incorporún a la Universiddad. Desde el año de 1704 en que ernpezó a funcionar, hasla 1722. cérca de 50 personas, en su totalidad religiosos. fueron incorporados y graduados. llegando a las cátedras muchos de ollos.

Tonemos entre manos la relación de todos estos graduados y muchos olros datos re. ferenlea al desenvolvimiento de la universidád crisloforino. documentos que serán prosenlados oportunamente en un estudio especial.

Dasde el año de 1722 adelante, las clases se desenvuelven normalmente. Egresan de sus Claustros, y enseñan, maestros verdaderos, bislanos citar al Doctor José María Montaño, gue por sus inquiétudeso tdeas gevolucionarias impartidas a sus alumnos. es comparable a nuestro muy recordado maestro Don Toribio Rociriguez de Mendoza. Por

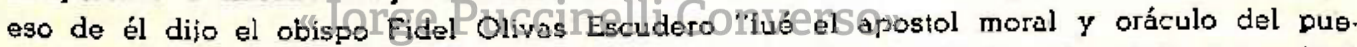
blo huamanguino". Al igual que Montaño tenemos a Ramón Muñoz, Angel Pacheco, José Maria Galvez. Marcelino Cleto Sáez, Pedro Urquizo, Benjamin Sáez, Octavio Cabrera, Samuel M. García, elc., y Juan Pablo Villanueva, admirable y connotado opositor a la clausura de la Universidad con sesudos articulos publicados en los periódicos de Ayacu. cho como "El Dorvenir". Insistimos en estos punlos, para demostrar que la Universidad de "San Cristóbal de Ayacucho" fué una institución digna, de prestancia académica, en donde se forjaron prestigiosos intelectuales, que dieron honor a Ayacucho y al Perú; en sus aulas onsefaron maestros verdaderos, que vertieron su sabiduría a los educandos ávidioa del conoctmiento.

Pero el objeto fundamental de este trabajo, es dar a conocer en su integridad las CONSTITUCIONES DE LA UNIVERSIDAD DE SAN CRISTOBAL DE AYACUCHO, como un aporte a la historia de la educación nacionál, y también como un homenaje a la Vieja Casa de "San Marces" con motivo del cuario centenario de su fundación, en mi calidad de alumno de ella, y ccrno un galardón que la fenecida Universided hubiera ofrecido a 3a Hermana Mayor.

Las Constituciones en referencia (8), íueron dadas exclusivamente por su fundador el Docior Don Cristóbal Castilla y Zamora, de vida parádojal, virtuoso religioso, natural de la ciudad de Lucena (España) (9), hijo baslardo del Rey Felipe IV (10), el 13 de julio de 


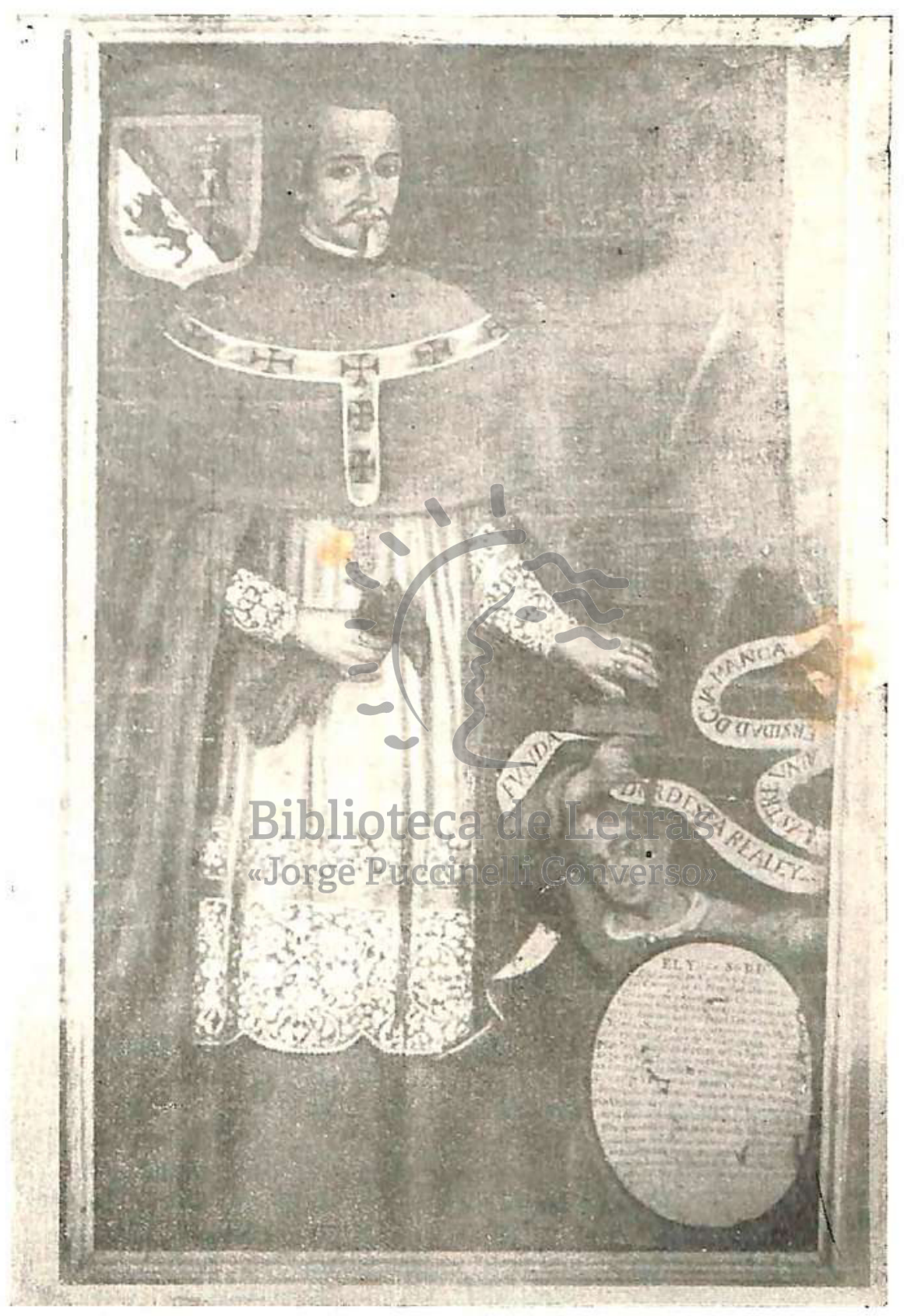

Ilustre Obispo Doctor Cristóbal de Castilla y Zamora, tundador de la Universidad de Ayacucho. Retrato que se encuentra en el Seminario de San Cristóbal de la misma Ciudad. 


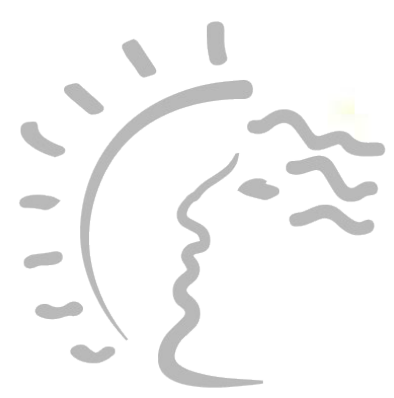

Biblioteca de Letras

"Jorge Puccinelli Converso» 
167. I sea, diez dias después de su fundación. Funcionaba entonces en la Univeraidas cuistro rútedras: Gramálica. Artes, Visperas y Teología (11).

Lu ascendencia de esto Prelado, resulta asi muy imporlante. Cuando el Dactor Cas:1112 y Zutmora llegó como obispo de Ayacuinco, se le hizo recepción tan nolable, que Prelado alguno haya sido objeto hasta enionces. Oigumos el acuerdo del Cabildo de !humanga (12): "todos los vezinos y moradores, se junten acavallo en las vassas de Cuvildo Para salir a recivir a Su Señoría Docior Xtobal de Castilla y Zanors, obispo de esta ciuciad hasta fuera de los muros desta ciud. como ssido costumbre y que los yndios naturates pongan arzos de iegoci;o Para las calles asta la Yglesia Mayor y ansimismo arrbas parroquias de arriva yabuxo salgan al uso del ynga con mucho lucimto. son sacar armas de fuego, $y$ echen sus vandos los Alcaldes para que no falle ningun yno. natural aloqueseles ordenare". Es que, el pueblo ayacuchans anticipaba su gratitud, por los eminenles servicios que más tarde iba recibir de este digno religicso "quien gozando por esta causa de valimento en la Corle, pudo hacer grandes benelicios desde el año de 1669 en que se hizo cargo de su alto puesto, como la erección de la catedral qua se consagró solemnemente el 19 de marzo de 1672" al decir de Enrique Gamarra Hernández.

En uno de los acársites del acta de la fundación is la Universidad te San Cristábal dice el Monseñor: "häbiendo entrado al gobierno de nuestro obispado y reconccido por el liempo a que lo gobernamos la falla de sujelos que ha avido $y$ ay en él, gor no habs: en estir ciudad donde estudjar las facultades de Aries Y Teología y las demas qie se requiere... emos dispuesto y ordenado para honra y gloria de Dios... de hazer $y$ ordenar ciertas Constituciones". Sin embargo ưue lo obłuvo, no vió funcionar la Universjdad por haker sido trasladodo al arzobispado mencionado anteriormente (13), y en 1 . Universidad de Chuq̣uisaca (14), que lleva el nombre de "San Francisco de Javier", prosigue haciendo bienes, porque también funda dos cáiedras: dos eran de Cánones (de Prima y Teología), y una de Institula.CCa de Let1aS

Castilla y Zamora anies de abandonar Ayacucho envia al Rey el Acta de la Fundación $y$ las Constituciones. El lass apruebar y conforma, mantestando "que se guarden y observen las Constiluciones con que fué hecha" (15). De la misma marera Su Santidad Papa Inocencio Yl dice en Su Bula: "deseando condecender faborables quanto podemos con el Señor a las súplicas que en nombre del mismo Rey Carlos humildemente se nos ha hecho por el ya nombrado Marqués Gaspar benignamente inclinados de consejo de nuestros Benerables hermanos los Cardenales de la Sanla Yglesia Romana Ynlérpretes del concilio Tridentino después de maduro examen hecho por los mismos cardenales confirmamos y aprobumos con authoridad Apostólica por el thenor de las Presentes las sobredichas Constiluciones de la Universidad de Guamanoa y las damos fuerza de firmeza Apostólica inviolable" (16).

Así nacen las Constituciones de la Pontificia Universidad de San Crislóbal de Ayacucho, que sirvió de paula, de nervio directriz, de guía, de antorcha, a la iuventud estu. diosa de Huamanga. Examinando con detenimiento, vamos, que muchas de sus parles se adeiantaron a nuestra época. Claro es, que olras, son similares y quizá repeticiones a las Constituciones de otras Universidades como de Lima y Cusco, pero, con todo. conslituyen una preciosa fuente para nuestros estudiosos.

El Doctor Diego Ladrón de Guevara, Virrey del Perú y Obispo de Ayacucho, fué in nuestro concepto el reorganizador de la Universidad, porque con él ella inicia su funcionarriento: a su empeño se debe el PASE de la misma y la elaboración de otras Cons- 


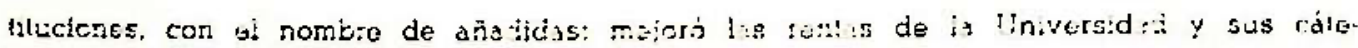

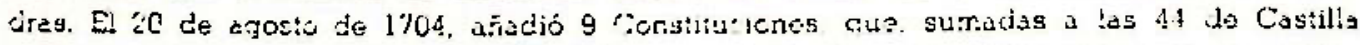

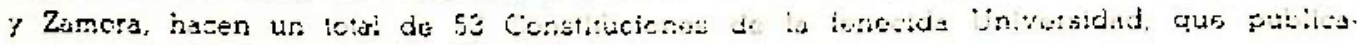
rugs or. su tololided.

Lir.i. 12 de theye de 1951.

Vidal Galindo Vera.

(1) Revista "Letras". Fac. Letrás Universidad lfacional hayor de San Marcos. 29 cuatri-

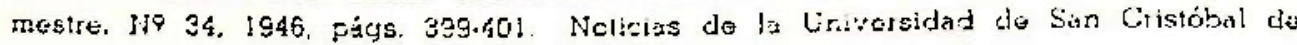
Ayecucho y del periódico "El Por\%enir". Fur Vidal Galirido Vera.

(2) Legajo de la Unjversidad de Sart Cristósal de Ayacucho, gue so encuentra on ol Convento de Sar Erancisco de in misma cirdad. Los dos mentoriales, correstronden a los años de 1702 y 1703, en el primero firman: "Dostor Don Bernardo Zumudio y de los Ynfantes - Doctor frontiges Alínso Guress - Docto: Don francisco Csrasco de Orozco -- Doricr Pedre de Aslorga 7 Figueroa -. Fray jaseph de Ascaray - Fray Ygnacio del Camro -. Dortor Den joseph Carrillo - Dector Dor. Martin de los feyes y fickta - Firy juan de la Pejía - Doctor Don Pedro de la Peña - Docior Don juen Cabero de Toledo - Doctor Don Bar. tholcme Romero - Doctor Don Diogo do Monlero del Ariuila - Don Gerónimo de los Reyes $y$ Rorha -. Dostor don Anlonio Fuxatcio - Doclcr don Bartholome Xirrenez Lobaten - Froy Pedro de la Peña - Doctor Der Agustin da la Serna dó Hàro Sertelario" En el Segundo memoria! lirman: "Dr. Don Joseph Gonzolez Terrones E- Don Pedre de Astorga y f'igueros -.

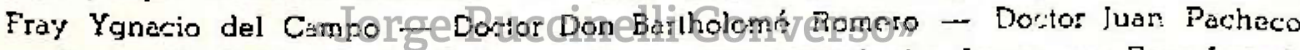
- Doctor D. Pedro de la Peña - Doctor Don Miguel de Arnao - Fray Josgijh de Zevallcs - Docior Don Joseph Gonzalez Terrones -- Don Gregorio Barrelo da Castro - Doctor Den Juen loseph Sänchez de Barreda - Don Diego de Zuráte -.. Don Joseph Tamayo de Jalacar - Doctor Don Fodro de Revilla - Don Agustín de la Serna Haro Secretario".

(3) "El Sol del Nuevo Mundo" de Francisco Montalvo. En Roma. Ymp. Angel Bor. nado. MDLXXXIII, páa. 77 .

(4) "Monografía Histórica de Ayacucho" de Luis R. Foviler. Imp. Torres Aguirre, 1924, pág. 85

(5) "Las Universidades Menores" de César Antonio Ugarte. Imp. "del Centro Edito rial". Lima. J916. pág. 24.

(6) "Apunies para la historia de Ayacucho" del obispo Fidel Olivas Escuders. Inp. Diocesana. Ayacucho 1924, pág. 256.

(7) "Libro de Grados de la Universidad de San Cristóbal". Se encuentra en el Conver. to de San Francisco de la misma ciudad.

(8) "Litro Cédulas y iundaciones del obispado de Guamança". Manuscrito inédito ds $371 \mathrm{ff}$. ítiles, lo posee un vecino distinguido de Ayacucho rosidente en esta ciudad, que me sirvió para copiár las Constituciones de la Universidad. Este libro contio 
ne además: Ediclos, aprobaciones, bulas, Reales Provisiones, Aulos del Tribunal, Cartas Pastorales, memoriales, escrituras, referentes en su mayoría, al obispado c:13 do.

(2) "Consituciones Sinodales del Obispado de Guamanga" por Cristóbal Castilla y Za. mora. Lima. Gerónimo de Contreras, 1677, pág. 5.

(10) "Nobiliario de los conquistadores del Perú" de Enrique Gamarra Hernández. Emrresa Grálica T. Sheuch S. A. Lima. Perú, 1938. pág. 93.

(11) "Diccionario Histórico Crenológico de la Universided de San Marcos"'. de Luis Anlonio Equiguren. T. I. Imp. Torres Aguirre. Lima, Perú, 1940, pág. CCXX.

(12) "Libro de Cabildos de la Ciudad de Guamanga". 19 enero 1675 - 19 enero 1675 , pág. 204 .

(13) "Husmunga Vindicsda" de Ramón Míñoz. Imp. "González". Ayacucho, 1942, pág. 18.19.

(14) "Chuquisaca" de Jaime Mendoza. Ed. "Charcas". Sucre, 1939, pág. 76.

(IS) Cédula de la Iundación de la Universidad: 31 de diciembre de 1680.

(16) Buls de Su Santidad Ynosencio XI: 20 de diciembre de 1682.

Tanlo la Cédula, como la Bula, se encuentran en el Convento do San Francigao do Ayacucho, conlormando un libro especial.

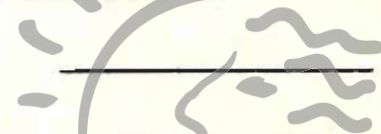

(f. 222) "Eı el Nombre de la ssma Trinidad Padre Hijo, y espíritu Sanlo, tres per zonas Distintas y un solo Dios Verdadero con cuyo Principio todas las cossas tienen msdio Loable y dichoso fín $=$ Se Panquantos esta carta vieren comonos el Doctor Don Cristoval da Castilla y Zamora obispo de la Santa Yglesia Cathedral de esta Ciudad de Guamanga de las Provincias del Peri/ =- Decimos que por quanto haviendo entrado. al Govierno de este nro obispado $\mathrm{B}$ reconcidotoepor el tiempo que aquelo Gobernamos $Y$ la faita de sujetos que á avido $Y$ ay en el porno haver en esla Ciudad donde con la ccrnmo-

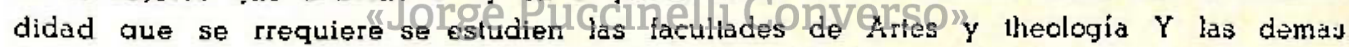
que se rrequiere por la suma pobreza delatierra; Y Reconocido asi mismo quede aver donde sepuedan estudiar dhas facultades los hijos de la lierra se aplicaran aellas $Y$ no solo estos sino que ocurriran deotras muchas partes aesia Ciudad aestudiar dhas facultades. $Y$ haviendo considerado lo rreferido con el maduro acuerdo quedevemos enos resuelto, Dispuesto $Y$ ordenado con el favor yamparo divino de Ynstituir $Y$ fundar una Universidad enesta dha ciudad con el título del Glorioso Martir San Christovarl y debaxo deel anyaro y Patrocinio Real del Rey nuestro Señor Don Carlos Segundo que Dios Guardo muchos Y lelices años paraque enella Yacosla de nuestro Patrimonio se estudien las facultades de Artes, y Thelología $Y$ lás de mas cue abaxo iran declatadas por todas aquellas personas assi deesta Ciudad come deotras qualesquier partes quesean quo quisieren aplicarse a las Letras $y$ para la cual $Y$ que siempre Permanezca dha Universidad firme y constante haviendolo mirado con el acuerdo ydeliberación que combiene casso lan grave emos Dispuesto y ordenado para honrra y Gloria de Dios nuestro $\mathrm{S}_{2}$

(f. 222v.) ñor y de su Bendila Madre / _____ La Virgen Santa Maria nuesira Señora Concevida sin mancha ni deuda depecado original en el Primer instante de su ser $Y$ para el mayor bien detodos açuellos que se quisieren dar asemejantes estudios dehacer y ordenar ciertas Constituciones y ordenanzas parasumejor Gobieno y Policia que su tenor son como se siguen $=$

- del consyo del rey ruvéro secinos 


\section{CONSTITUC:ONE:}

LE LA UHTEKSIDAD R.. FUMSADA EN LA CUUDA:

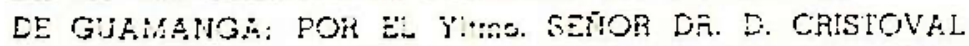

Y ZELOEA, OBISPO DELLA DEL CONEETO LEL GEY MKO. SR.

CONST. :

\section{Del Titular de la Universidad}

\$. 1. Tiene esta Universiad por Tilitiar y Putan a Glo:ieso Martir San Crisloval for aer nerrbio dei tundacer $Y$ acsi licne on el Gerietal mayor altar $Y$ su ima-

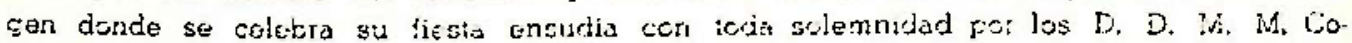
llegiales $Y$ estuciantes por ia intersion dol fundador, hntes de comenzar primeras Vis. perás saldra enforma la Universitad upie a dar un faseo por la flaza mayor en con. :orno ccm el estandarle Yasignius. mazas yatavistes =

\$. 2. de la misme forto pero acavelto irs la univorsidad al monasterio del Car. mer o de Sanla Clara ei dis je Sunis Cataina aveinte y rinco de noviembre aceletrar

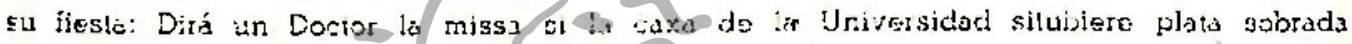

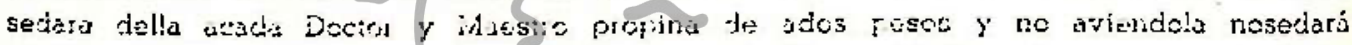
propina, el dia de lis oftuva dela Sania eritrata la Universiand en jorme con estondarte. Yrsignias, ynazas y el Collegro adecis una missa canleda enla Copilla deSanta Catalina que sirve al Sagrario cuyo uso emos Donsda a la Unjversidad y al Collegio $Y$ la misa se dira for los aciertos y feliciciad de la úniversidad. =

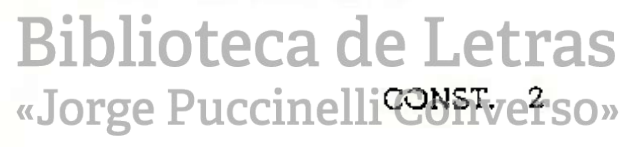

\section{Del Oticio de Rector}

§. 1. El Reclor de esta Universidad scade eiejir en cada un zaro un día des(i. 223) Fues del de San Chrisicval, por la mañana, votando / -....... el Fector, el Chan. ciller, los D. D. y M. M. cada une con un voto y seacleesta: a la mayor parte de los volanies, $Y$ si salieren iguales pervalecera la mayor paste por quicn hubiere volado el Recto: Y si pareciere a lá Universidar quelos volos sein secretos, so votará enesa forma, el que hutiere de ser eijijido Rector adeser Doclor. O Maestro, o ircorporado en esto Claustro, ysepermitira que se pueda elifir a alguna, de las tres primeras Dignidades deesle Cavildo Eclesiastico de Guamanga, aungueno ssan Doctores, Maestros ni Licenciados: No podra ser Reeleșido la dho Dignidad ni otro del Cavildo Doslor o Máestro porque gocen de la Dignidad de Rector los Dociores, y Maestros y si por altuun accidente se hubiere de hacer Reelección adeser con lodos los votos conformes, y pura que no se taga baslará que un sólo voto lo rrepugne y haviendo de juntarse el Claustro a de ser per conbocatoria porescrilo del Rector Y llamamiento de ono de los Bedeles; $\bar{Y}$ estando auserile de la ciudad mas de doce leguas, o no aviendolo conbocata el Dontor mas antiguo; àeste oficio de Rector perlenece el oficio de la Universidad vease la Constitucion once que trâla delos que no tienen Voz pasiva para Rector. 


\section{CONST. 3}

\section{Del Oficio de Chanciller}

§. i. Despues del ofitio ciel Rector se sigue el oficio de Climciller de la Univernidit sarien toca la inmediata superintendencia de los estudios yesie adeastar siemits en li rorsona qute fueto Provisor en sede plena. o sede vacante y adetener el primer asianto despties del Rector: quando el señor Obispo no pudiere dar el grado io scmoterá a el Chanciller: $Y$ lá sede Vacante ara lo mismo $=$

\section{CONST. 4}

\section{De la Aprobacion Dara Grados}

\$. 1. La sacultad dedar la aprobación para los grados compele al Recior, Chancilier y Doctores deesta Universidad y si hubiere muchos Doctores entraran al exsmen los quatro mas antiguos como sedira adelante desde la Constitucion nuebe, y desce Is Visite $y$ cinco $y$ enlictanto gue no hubiere Doctores, ni Maestros ontraran aser exsumizadoros los Lectores y los exsaminadores sinodales y!levaran las propinas del exsamen como Doctores $=$

\section{CONST. 5}

\$. 1. Si el Señor obisfo quealoresentees, oadelante fuere quisiere / - - - - - -

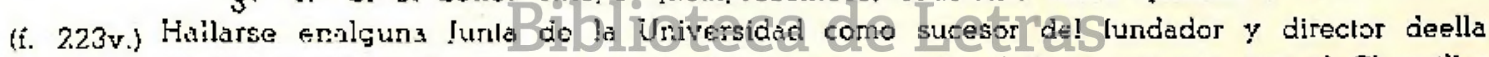
lendia el primer Lugar, y se le seguiran dot un lado el Rezlcr, y por otro el Chancilla: yluego los Doclores, ydescrues los Mafestros por su amiguedad $=$ Y haviendo desalir alyun paseo de grades yran los Dottores sin el Rector y Chanciller atraer al Dxctorando ala liniversidad yde alli saldre e! paseo precediendo el Reclor yacavado el pases yran los Doctores con el Doctorando allevario a su casa; pero en el paseo yra el Rector al lado derecho del Chanciller yel Doclorando delante del Rector $y$ inmediato enire los dos Doctores mas antiguos $=$

\section{CONST. 6}

§. 1. Todos los años veinte dias anies dela Dominica in Albis quees quendo serncie comenzar los esludios haga el Reslor poner $y$ publicar edictos para que lodos los estudiantes y collejiales oue prelendan Graduarse Ganar curso, y gozar delos previlegios de la Vniversidad se matriculen, y juren la obediencia al Rector dentro de otros Veirte dias dspues de la Dominica in Albis yqueno matriculándose en el dho termino no gozaran conc seestatuie quenogocen de los dhos jrevileģics ni puedan ganar curso en las iacultades que oyeren y se quardara lo dispuesto en la Constitucion Diez y nua. ve $y$ Veinte. 
CONST. 7.

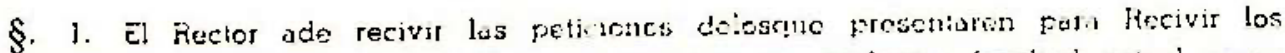
grates mayores, omenores de Peligiosos. O seruhares on cuslquier laculiad antect socre. tario de la Universidad y asi mismo las informaxiones do los cuisos y calldacl, y las cartas, ytilulos que presenlaren, ylas exsanme ysihubiere alguna duda la comurifue con el Clausiro, ynose admitira argrado mayor do Kaesiro. Licenciaclo. o Doctor perscisa que nosea de Lezitimes Padres ycondecorada, sin nota de sangre de costumbres. de Yrresularid - deexpulsión ydepersona demal aspeclo; ysiendo admitida lapresentación. si fuera para grado de licenciado. Maestro o Dazlor, mandara roner editios paraqueles Bachillo. res quepretendieren tener derecho de Antiguedad para el grado de Licenciado olos Li. canciedos para el de Maestro. O Doctor parescan apedirle ypresentarsa dentro del termino quelos edictos señalaren yestepasado pierda sil derccho deantiguedad ylos dhos editos vajan írmados jesolo el Rector yel secretario ysellados con el sellopequeño / de la Uni. versidad como sc dira en la Constitución treinta ycinco parragrato Primero.

§. 2. Los Religiosos que presentaren Graduarse o Yncorporarse andaliàer certítcociones autenticas de sus cursos dadas porsusprelados; yandeparsar por los exsameres rigurescs como los que vinieren a Graduarse o incorporarse de Universidades da Fieligiosos y serrefiere adelante en la Constitución quarenta y dos parragrafo segundo pero sisus grados fueren de Lima of Universidades insignes se Recivira como manda la Constjlución quarenta ydos parragtalo Primero.

\section{CONST. a.}

\$. 1. Entcdos los cassos enquehubiere de Ynterbenir juramento lo Reciva ol Rostor, yesto seú assi, en los que se graduaren en publico como a los que se recivioron - incorporaren en la Unversidad Do los que Reciviefen oficio enella, limandolo el Reclvido, al Rector. yel sectelafio. poro en las delerminaciones de los claustros, flrmán al Rector, ylos votantes, autorizandolo el secrelario, La lorma del juramenio esta al ín deeslas Constituciones.

CONST. 9.

§. 1. Ael oficio de Chanciller toca ver las Conclusiones quese lubieren de defender. señalar de los M.M. y D.D. de la Universidad los que ando Arguir alos exsa menes que seran quatro delos mas antiquos deaquella faculiad y a lalta deellos onira ranlos Cathedraticos de la Universidad y a falta deeslos los exsaminadores Sinodales.

\section{CONST. 10.}

§. 1. Enel Archivo dedos llaves queadelener launecl Recler ylaolra el Secretarto se guardaran las Cedulas Reales. Bullas, y Provisiones, lecantes ala Universidad, los Ljbros donde se asientan los grados yteslímonio deellos, Las formulas delas cartas, o titilos deloz grados por que alodos. seden por un tenor, yla plata que cayere de derechos de grados de alquna pena, o multa, $y$ de otro efecto que pertenesca a la dha Caja dentro 
cintuqual estara un libro donde seasentara lo cue entrare, osaliere deella, ynose gastara s:no cs encesas pertenecienles a la Universidad con expresa nuencia del Rector y parecer dei Claustro.

CONST. 11.

(F. 224 v.) \$. 1. Todos los D.D. ẹue fueren graduados o incorporados enesta Universidad $y$ l.os Mi.M. entren at: los Claustros yse / hailen en los actos públicos deella ytengali votos legitimos aclivo y pasivos como Capitulares deella fero paraelolicio da Recior eniren enel Claustro yleng̣an solo voto activo el Chanciller, los Feligiosos graduados e incorporados enesta Universidad ylos lectores deslla actuales de Theologis y Alies como si fueran graduades seritandose los Ulimos los Cothedraticos yarriba deellos ios M.M. y arriba deeslos los Doclores, aunque semn mas modernos. y los Calhedraticos no usaran de Ro:k ni Capirote enaclo alguno hastz questen praduados.

§. 2. Aviendo de estar juntos los dos oficios de Chanciller y graduante en el Fro. visor no zo: esso adellevar dos propinas sino la de graduanie quanco diero el grado. 7 no de Doctor, $y$ no dando el grado llevara mropina de Dortor.

§. 3. Yonla opesición delas Cathedres que se hubieren de proveer tendran voto ol Fiector, Chanciller, Doctores. Maestros y Cathedraticos autuales de Artes y Theología un volo cada uno para que se provean por mayor parte. Los Cursuntes Bachilleres, Y 1.Jcenciados, notendran voto por que seescusen inquietudes.

CONST. 12.

§. 1. For la estimacien queesta Universidad devetener del Cavildo eclesiastico doesta ciudad sirlguna Pignidad. o Canonigo se graduare de Doctor, o Maestro, ose yncorporaro enesla Universidad tençan despues del Rector sus asientos interporlándose conotros Dorlcres anliguos siguiendose poin uho yotrol lado.SO

\section{CONST. 13.}

§. 1. Los D.D. y .M.M. deesta Universidad procuren tener entresigrande correspondencia yomor $y$ quando fueren llamados a las fiestas, grados, oclaustros, vengan con Funtualitlad sino hukiero algun legitimo ynoedimento y sialguna vez fueren combocados pisratratar algun riegocio tocante en bien dela Universidad lo agan con la gravedad y modestia que comione $\sin$ escusarse ysi seescusaren sin causa lexilima les pueda multar el Inector yobligarlos su .pena presztite yel votar enel Claustro. Ydar su parecer guarda ran buen orden y con ciorto comenzando avotar porel Doztor mas ontiguo ydespues los iM.M. los Catedráticos actuales ysera el ultimo el chanciller $y$ despues el fiector.

CONST. 14.

(f. 225) \$. 1. Murtendo algun Docior o Maesiro yra la Universidad / - - - en forma con luto y mazas al entierro el estandarte no yra enel acompañarniento pero se pondra 
eun lado jurto al lumulo ysobreel cle fumbia dral ditunto oepondian tas ansignias Docters les a Magistrales jesugrado ol cepirote Boncie cell su boiln y sus Armas yjentro deun mas selearan sus honras y dira la mis contada tin: de ies Dateres o Marstoos.

§. 2. Haremes donacion crte bivos del usso denuostr capilia de Sunta Catalina que tambien sirvo ael sagrario de la Cathedrai aosta Unizersidad y Collogio Seminario

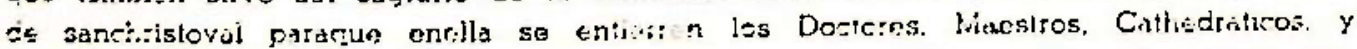

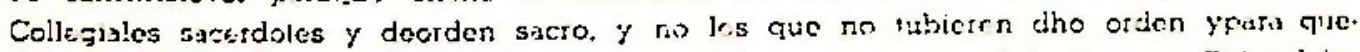
los ausodichos digan missa enella y enyde: dela conserbucion dola lam!ara hejayalajas deello lacual nes pertenece por litulo $\gamma$ eseritura de Trece de Marzo de mil y seiscientos y setents aros ante Juandosutsa eserivano publico de Guamanta cuya coria eslaenel Árchizo del Camarin de Nuestra Secretaria quaderno i-rimero o 1.2 y de cads apertura de sefuliura separaran dos pesses alalabrica de la Cathedrul.

CONST. 15.

§. 1. Enrsta Universidard insiluimos quatro cathedrés la primera do Gramatica, la serunja de Arigs, la lercera de Visparas. de thoologia enqued Maesiro arieleer oncada

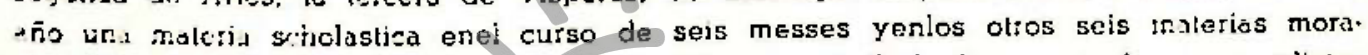
las: Laquarie do Puma de thevionia alas quales quatro Cathedras sean de poner edictos yse an do lomá tres punlos eszojiendo el oposilar el auedellos le pareciere para leor aiss veinte $y$ cuetro oras por Relox de Arena: A lomar los puntos se hallara el Rector. ei chanciller, yel Secrelario que dara tee ylo escrivirs enel !ibro. Asimismo si quisieren schallaren presenles les opositores ydesputes de aver leycio en publico on el General mayor o en la Cathedral Arguiran dosdelos ofosilores por turno cadaune cor dos modios, Asistira a los actos la Universidad plenz y los Cathediaticos auluales paraquehagan juicio de los que hubieren de votar.

§. 2. Par la cathedra do Gramalica sean de-tomar punlos en el Arte de Anlonio fára la de Artes en el Philopho, para ladeiheología en el Maeslro de las Sontencias.

§. ง. A las bposiciones secadinititan Clengos.r. Beligiosos y seculares que por lo tnenos lengen el grado de Bachiller.

\section{CONST. 16.}

(f. 225v.) §. 1. Dotamos las dhas quatro cathedras en la lorma siguiente / - de ochocientos po. ecs que gana de alquiler nuestro Palacio y Cassas episcopales junlo a la Colodral, y de los alquileres de catorce liendes que salen a la calle y de la Notaria mayor quessiá en el zaguan queestoda obra de cal, y canto, fabricrda y pagada de nuesiro Patrimoniu en piecio de cinquenta $y$ nueve mill y quinienlos pesos como consla de escriplura de trece de mayo de seiscientos y setenla años ante Juan de Asursa escrivano publico do Guamanga; escriptura de veinte y nuebe de marzo de milseiscientos y setenta y quatro añoz ante don Francisco Benegas escrivano de Cavildo de Guamanga, edilicadas en los solares que compramos por escriptura de doce y veinle y sicle de tebrero de mil y seiscientos y selenta y lres años anle Francisco Blanco escrivano do cavildo de Guamanga, yescriptura de diez de marzo de mil y seiscientos y setenta $y$ quatro años ante el dho don Francisco Benegas, $y$ en un censo de un mil ps de principal que nos paga 
el Licencinto Juan Martincz escrivano cura de Tambo, yotoca por escriptura de veinle $y$ sicte de junio de mil $y$ seiscienlos $y$ setenta $y$ dos años. $Y$ Foconociniento de quatro ic jullio del mismo año ante el dho Francisco Blanco.

\$. 2. El Rector cuydara siempre que llegue el casso deeslar desocupado el Palario Enisropal gue donamos a la Universidad de queno se maltrale poniencio quien lo surde yias cerraduras, tablas, asienlos, estanles del linelo y Libreria $y$ todo lo demas, nerciue re viya on Disminucion esta finca enque esla Ympuesla la Fenla de las CatheIris. yel Reclor dora las llaves de las tiendas, a los cathedraicos queles tocaren para r:to las alrstilen y mientras durare la vacante del Palacio hublese personas honestas ciuc anicnden sus quartos, los alquilara el Recter porgueno cesse de correr la Renta.

CONST. 17.

§. 1. Hacomos Reparticion de las dhas Rentas y tiendas en la forma siguiente: I,as crises que tenemos entrela cathedral yel cavildo secular, lenenios dadas al collegio de san christoval queliene si hivienda ylodas sus oficilus en lo interior. Pero ta parte que sale al cementerio dela Yglesia yalaplaza donde eslan los Generales. lacapilla para la Lcctura delas Cathedres de la Universidad ho, solo ade servir al collegio como parece do la Corstitucion primera delas que le dimos, sino tambien a la Universidad en vitrtuci doesta Constitucion.

Jotación De los ochocientos pesos quean depanar de alquileres los prelados que bivieren en de las el Palacio episcopal señalamos por año trescientos pesos de Dolación para la CatheCathedras dra do / __._. Prima de Theologia y mas las tiendas delos (t. 226) tiumeros Pimere, quato, seplimo, $y$ decimo, que gana cada una por mes quatro pesos y montan al año ciento rovenla y dos pesose A lactathedra de Visperas de Theologia enque acteleer el catedralico sejs meses materias scholasticas y otros seis del mesmo añ materias nores les sefilangs de estipendio por año docientos y cinquen!a pesos en los ochocienics pesos auegana el palacio episcopal, y mas la trenla delas tiendas del nu. mero dos, cinco, ocho $y$ once que a suatro pesos por mes montan al año ciento y noventa $y$ dos pesos.

A la Cathedra de Artes. señalamcs para cada año Doscientos pesce en el alquiler clel Palácio Episcopal ylas tiendas del numero lercero, sexlo, nuebe $y$ doce que aquatro pesos per mes cada une montan ael año ciento y noventa y dos pesos.

A la Cathedra de Gramatica le señalamos por año los cinquería pesos de ceridos del censo de un millpescs de principal yla notaria mayor quegan a cada mes seis pesos y la tienda del numero catorce que gana cada mes tres pesos, y lodo junlo r.orta cientc y cinquenta y ocho pesos, a losquales cathedraticos se les andedar las llaves delas thas tiendas para que corran porsuquenta como estadho, ylos cinquenta pesos que sobran encada año delos dhos ochocientos pesos los Reservamos para los reraros que seotrecieren en el dhe Palacio y se los reparcs importaren mas de los cinquenta pesos los suplira el prelado quelo ccupare de su quenta, porque la dha Dotacion de les Cethedra noscade Diminuir y conestas calidodes y no con otras seade ocupar el dho Palacio, yel Rector, y Claustro, cuydara deque sepaguen las dhas Cathedras y 


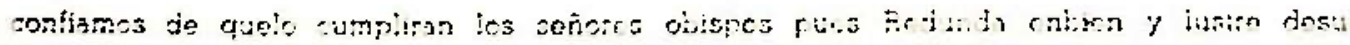

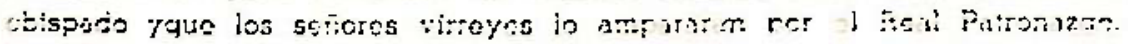

\section{COIST. 18.}

\$. 1. Paza el Vaestro del ento qunio ve ens

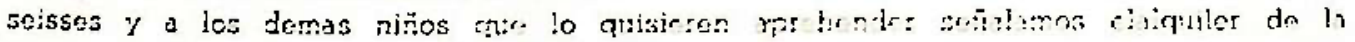

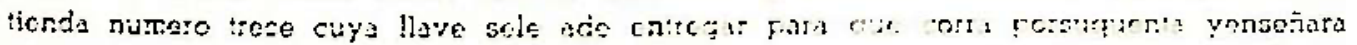

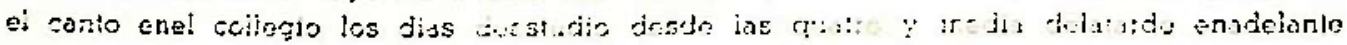

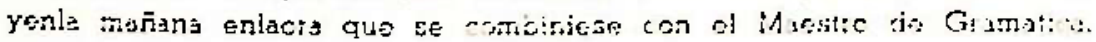

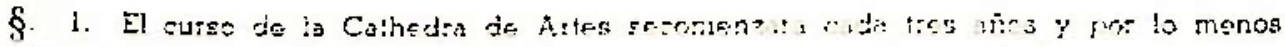

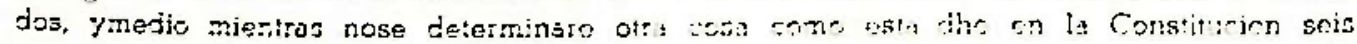

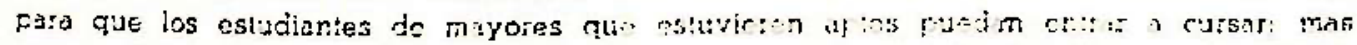
no se edrila alguno a la matricula delpimsi curso jin Cedul- del Maestro de GromaIlca ayprobacion del Chanziller.

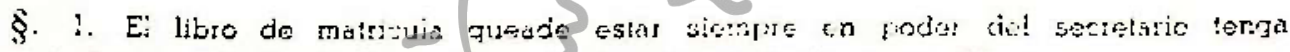
la matricula de cada iscultarl por abecedarrio yseade drchar en elt fara quo curso se ratricula el estudiante. Diciendo ertantos detal nics y año se millkuló natural detal parle paro oir el primer curso de Artes trajo Cedula del iricicsiro de Granutica yaprobacion

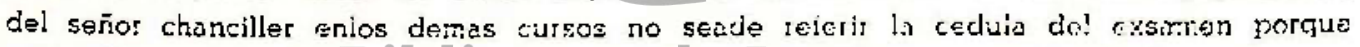

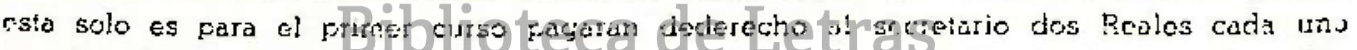

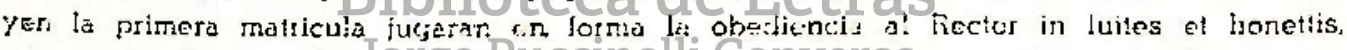

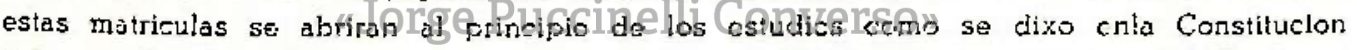
seis pasado el quäl tiempo ninguno se podta matricular sin disfensacion del Rector y ceusa lexilima sino fuere persona demuchios prendas yesperanz.

CONSTI. 21.

§. 1. Por la mañana sean de lecr las Cathedras la de Prima de Theologia ylario Artes comenzando la de Artes desde las ocho a las nuebe $y$ la de Prirnta de nucbe a diez ypor la tarde la Cathedra de Artes de tres a ruatro yiade Vispcros de Theologla de qualro a cinco leyendo como esta dho enla Conslitucion quince los seis messez delaño materia Scholastica ylos olros seis Moral.

\$. 2. A las quales lecciones de Arles amañana y tarde ande asistir les estudiantes Artistas, Para ganar curso ylos estudianles theolorjos alas dos Cathed:rs de Prima y Visperos ycada uno de todos elles antes de ser admitidos a nuebo mairicula ancteiraer ceduliss de sus Maestros deaver cursado el año antecedente ytres lesilgos paralaprieba. tados los Maestros ande tener despues delas Lecciones por lo menos un quarto do hore do parte para oir las dificultades de los esludjantes yporla terde lendean conferencia los discipulos enpresencia de sus Maestros dedos alres, y los Artislis en el pilmet año de Lorgica 
For ser tan Ymporlanle tendran olra ora de conterencia por la mañana de nuebe a diez menos los savades que abran detener conclusiones un savado / F. 227).

(f. 227) Los Aristas. Yotro savado los theologos y cursantes de Moral ysi fuere el savario dija de ísia seantepondran las conclusiones porqueandeser irromisibles haviendo de huver exzimenes de Bes. o actos de grado mayor $y$ lecciones de veinte y quatro oras se señularan por el Ror. los dias enqueseandelener deforma que no estorven alos cursaniea nislas dhas conclusiones savatinas.

CONSTI. 22.

§. 1. Encada año abra aclos por lo menos uno detcda la theologia, y el siguiente nôo tcina clro aclo general el cathedratico de Visperas yasi seyran alternando el Maest:o de Aites lencira caca ar̃o acto do Artes $y$ el Litimo sera General detccis ellas, el do Theciogia sera por el mes de Mayo. los de Artes seran en el primer año por ol mos do ju:.'io. el del segundo ano enel ines de oclubre yel lercero sera antes de las vacaciones.

\section{CONSTI. 23.}

\$. 1. Todos los jueves del año seran dias de asueto portodo el dia para los de lacullad; y fara les Gramaticos solo por las lardes sinoesqueaiga alguna fiesla enla sswana que haviendola ese dí sera el asuslo, pero sera juebes enlero de vacanie el de la scmana de Pascua, deEspíritu Sante, la Vispera de Corpus por la tarde, yel dia de los difunies por la mañana la Vispera de rro. Patron de la Universidad Glorioso San Chrisloval, el dia antes de vacacion yra uno de los Bedeles ydeordinario sera el mayor nurs ànliguo con maza al ombro yllegandose alapuerla del General ara una Reverencia el Cathedratico y Dira: Sapientissi me. Magisler, Loni sini tibi dies crastina die habebetis asuelum mane et "Vespere, aul vespere tantum, contome" fuere la vacacion ypasara aotro Gen. adecir lo mismo.

CONSTI. 24.

\$. 1. Las demas vacaciones seran desde la Visuera denavidad inclusive hasta la Circunscicion, yciesde la Dominica Palmarum hastala Dominica Segunda post Pascha, quees cutncio sean de comenzar los estudios de facultaci dela misma forma los Gramaticos

(t. 227v.) tenciran estudio desdeel miercoles de zeniza / _____ Por la larde hasta la vispera del Domingo de Ramos porla tarde inclusive y esla cathedra seadeleer por la mañana desde las ocho hasla las once teniendo de suella y vacacion media ora para reparar cugadeser de nucbe y media a diez y por la tarde tendran descle las dos y media hasta las qualro y ma.. deesludios en el General, porque despues esludien el canto ytendrar. los Gramaticos Leccion la Vispera de Navidad y la Vispera deEspiritu Santo solo por la mañana las fiestas que son de Guarda en la Ciudad lambien lo son para la Universidad de los Parrones de los Religiosos. 
COISTI. 25.

Del Grado de $\mathrm{Br}$, en Artes

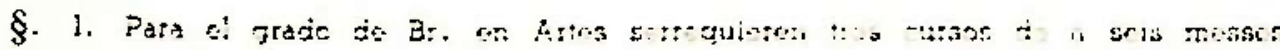

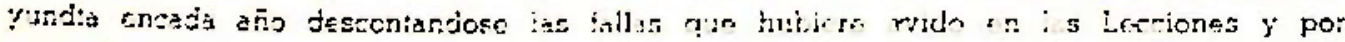

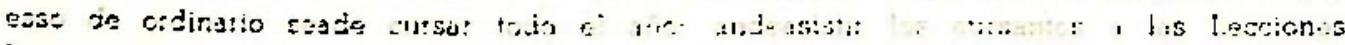

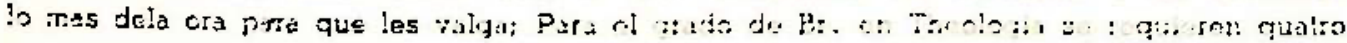

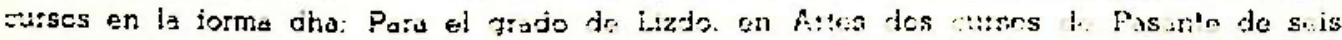

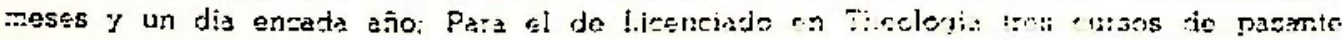

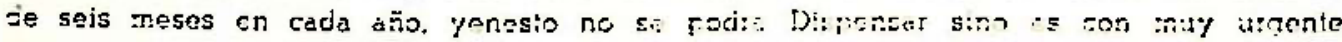

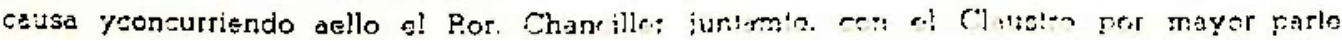
de rotos ycontribuyendose algung forcion pin lis $\mathrm{C} x \mathrm{x}$. of la Universitad yes declu.

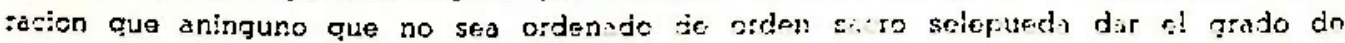
Lienenciado en Theologia.

\section{CONSTI $2 E$.}

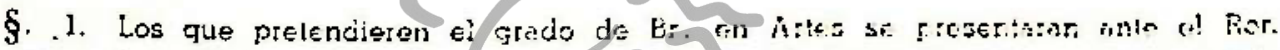

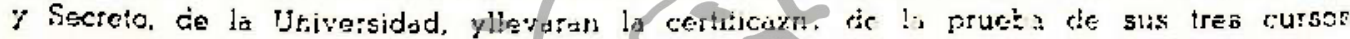

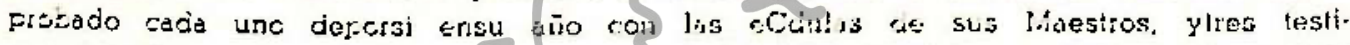
ges deaseis messes yurdia cads uno queson los que se riden en este graco por la

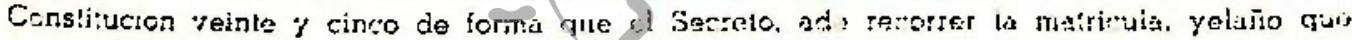
no la no le tubiere valdra, duntue prueb. que acursadic sits a: que el For con parescr

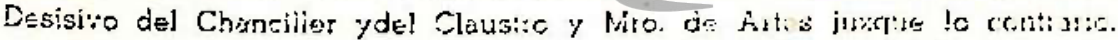

§. 2. Asi mismo ara intormacion deccino a loide tupete Lecciones enel Aula que

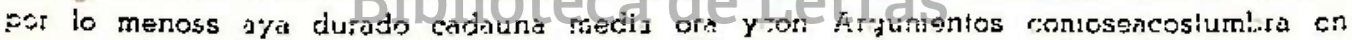
ias Universidades insignesorge Puccinelli Converso»

§. 3. Daro asi mismo el Secretario fae de como aderosilado por derechns del gra(f. 228) jo doce pesos uns se Distribuiran en la / _._. Iorma siquiento=z ala caja dos pesos. a] secretario un peso alos Bedeles acado uno un ceso. A los tros Arauienits si fueren Meestrcs, en Arles o Dectores en Theologia acida uno un pese, al Guduente dos pesos losdemas se rrepartira entrelos dela facullad queasistieren áigrado y sisobrare algo alo caja.

\section{CONSTI. 27}

\$. 1. Señalara ei Fector al Laureando el dija do si exsamen publico yparasl daract Graduando unpapel enqueaya Diez y ocho con-lusion:s, stis die Lojica, sois de fisicos. Y scis de Melafisica yanima las quales haviencicius regisläado el chancilier, las clara s! Rector a tres Doctores o Maestros dela Universidad, o a lics Cathodraticcis, y exsarminat dores sirodales como $z e$ dixo en la Constitucion qunrta ijevondo cáda uno deelins una copia para que Arguian ycadauno podra proponer ues argumentos siquisiere mas no

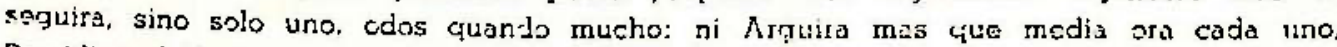
Presidira el Doctor mas antiguo dela facultad ccmo Decano deella yporsu falia el Doctor más anliguo que se siguiere. 
CONSTI. 28.

§. A. Para celebrar estos actos sepondra una mesa en medio con su sobra messá enquestura una Salvilia con ias conslusiones $y$ las mazas de los-vedeles. yentrados en juto el Rector. Doctores y Maesiros, yran los Bedeles con sus mazas por el Laureando. y ìtesidcnte yliecha Reverencia del Claustro sesubira a la Cathedra yel actuante seseniul delante enuanco rasso, yno ensilla porqueasta solo se pone para ol exsmen degrado :t!ıyor. O quancio ei graciusndo es Niaesiro yse Recive aigrado de Buchiller en theologia dicha la Resumfti quesera breve dara e! vedel las conclusiones ael Recio: paraquehaga síñal de quelasde akqueade Arguir en primer lugar $y$ despues por su orden sedaran atos otros, y sialguno de los graduandos tuviere acto detodas las Artes por mañana y taidc. levaldra esta acto por e! exsamen depositando primero los derochos $y$ haciendo uss demas rieguisilos.

CONST. 29.

§. 1. Acavado el eximen sejunlaran el Reclor, el Chanciller y el Maestro de AitGs, clos lectores de liteclogia y orros dos del Clausiro Maestro en Artes, y Doctores

(i. 22.8v.) gn Theologia que por lodos sean siete queson los que fueton / _._... señalados intes pura el exsamen yparadar su parecer $y$ estando juntos dara cada uno su volo delinitivamenle de priabra o por A.A., y R.R., hechandolas secretamente en una cajuela yle aprobaran teniendio suliciencia enuna mediania ordinaria en el entender ydefender, mas si esta mejiania le fallo no le pondran ni deveran aprobar yentesto encargantos la conciencia do los exsiminadores quedeven mirar por el decoro ybuen nomire dessla Real Universidad ysipareciere combeniente al Rector podra pedir juramento alos dhos exsaminaciores dequearan bien Yatielmente sul oficio.

\$. 2. Si $\mathrm{i}_{\text {el }}$ número de los R.R.i edelos que yocalmenle negaren el grado fuere mayor no se admitira enmanera alguns el exsaminado: mas si fuere menor asi tubietu alguna $\mathrm{K}$, seledira vocalmente ysele dara una buena Reprehension encargandole queestudie, eslos volos encontra sepondran en el libro que queda en la Universidad masenel titulo de Bachiller sepodra usar devenignidad ynoponerle las R. R.

CONST. 30.

§. 1. Estos aprobados andelener tres ordenes decalificazon. Primero de los que exceden insuficiencla yestos quantos fueren ande graduarse primero que los demas liamarndolos por suerte a recivir los grados, sino es que entre ellos aya alguno qua a juicio detodos los aprobantes seabentaje alos demas, segundo orden es delosque segun incios ios volos tienen la suliciencia necesaria, estos se graduaran despues delos primeros yeniresi guardaran el orden dho desuertes, tercero orden es delosque no tubjeron todos lns volos para el grado aunque lubieron lamayor parle, que se graduaran en el tercero lugar almoclo dicho yasi los aprobanles comenzaran adarlos votos con esta calidad, diciendo judico, $P$. excedere omnino suficientiarn requisitam adgradum, $O$, judico lantum atingere, o Judiconon atingere, esle modo se guardara quando se exsaminen todos olos mas deun curso para graduarse. 
§. 2. Dados los votes conformendese comolios daran $y$ inmursa ia aprobscion for

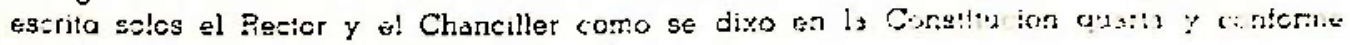
als icrmula quese pondtis al in de las Constituciones.

CONST. 31.

(f. 229) §. J. La solemnidad en dar les giafos de Bachiler en Ailes / - W - soru la

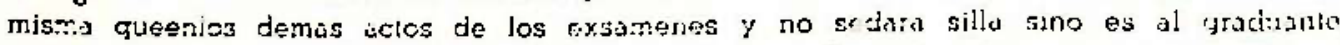

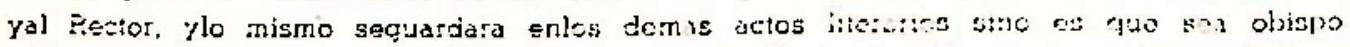
oidor o pielado mayor como Comisario, o Vicario Generul o lapersona aquten sededican

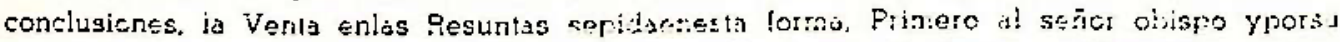
susencia alapersona queensunombre diete el grädo, luego el Recter. $y$ Chanciller $\gamma$ luo. go al Cerejidor despites a los dos Cavildos exicsiastro. yserulm, si conemieren. luego a la persona acuien sededica e lacto. despues alos Leclores Don:ores. 7 Mirestros. alos citcunsiantes 7 alquepreside en la cathedra, yosis misnic juirdara eloue Asgrimentare.

\section{CONST. 32 .}

§. 1. Los que fueren reprobadcs perdaran solumente del dinero depositado para el grado lonue hasta aquel dia sehubiere qustado. osederiers al Srctutario, exiaminatores yvedeles, $y$ geles bolbera el Resto dalo quo avian degastar en poopinas yotras cossas

\section{CCNSTi. 33.}

\section{Bib Grad dockr. en enéologia}

§. 1. Lo que hubierearge Gradurise del Bachillélenothoologix andeser primoro Eachilieres en Attesyen la forma desugrado seade guardar lo mismo que sendicho dei grado de Artes excopio lo siginiente, andeprobar quatro cursos de theologia aelfin do cada curso come est3 dicho ecn certifizacien delos Leclores dequem cursado las clos Cathedras de Prima y Visperas yandetener un aclo denuebe conclusiones, treg de cada parle de Santo Thomas, Arguiendoles tres theologos, Doclores. Maestros, o Leclores y porsufallalos exsaminadores sinodailss. Presidira el Decono delalacultad o, uno delos Doctores en Thelolcgia, Acavado elacto sejuntaran el Rector, el Chanciller, los dos lecisres de theologia yelde Artes ylosotros dos exsaminadores señalados ydiran su voto acerca dela sufictencla.

CONST. 34.

§. 1. Los Derechos queade depositar el Graduando sondiez yseis pesos, ala caja quatro pesos al secretario dos pesos, acada exsaminadar unpeso, alos vedeles acadano un peso al Graduante dos pesos, ylodemas serepartira enire los de la lacultad quees. lubleren presentes.

§. 2. Entodos los concursos Literatios, yqualesquiera otros dela Universidad procederan los Eachilleres en Tehologia alos de Artes. Yestes alos demas cursantes queno 


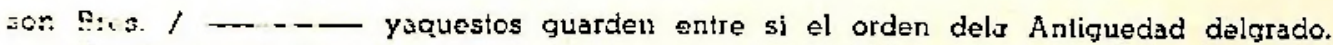
(.. arsw) \$. 5. El Graduando antes de recivir elgrado de Bachiller en theologia haga jurzwento enumtios! enmunos tee! Rector yenpresencia deles circunstantes deque siempre iundra yensej̃ar de palabrayporescrito aversido lasiempre Virgen Maria nuestra Señora Concevida stn pecido original yse pondra enel tilulo ccme hizo este juramento despahisndos:ic segun is fornuia quedespues sedira. Y este mismo iuramento andehreer lodics los que se graduren de Licenciedos. Maestros, Doctores enosta Universidad.

CONST. 35.

\section{Del grado de Lizdo. en Astes}

\$. 1. Los Bachilleres en Artes cue pretendleren Graduarse de Licenciados enla tha iacultad andeser pesanies dedos cursos enteros de aseis meses yundia despues que Recivieten elgrado de Rachiller, presenterarse anteel Rector. Chanciller y secrelario do la Universidad exsiviendo paraesto los tílulos originales delgrado de Bachiller hecho esto fondra el Reclor edictos itimados desunombre sellados con elsello psqueño dela Unjversidad Fefrendados de! Secrelario paraque siaiguno delos Bachilleres mas antiguos quisieren gozar delprevilegio yderecho quetienen para graduarse pimero paresca ante el Fector ysepresente dentro del termino señalado pasa Recivis el dho grado queordinariamente sera de quince dias, omenos como al Restor pareciere conapercivimiento que iasudo el dho termino perdere su derecho.

\$. 2. Depositara por defechos para el grado de Licenciado ala Caía doce pesos, al secretario ocho pescs a los vedeles acadauno quatro pesos, algraduanle seis pesos, al padrino seis pesos, a los. Dectores. OMaestros dela lacultad quehubieren exsaminado atres pesos, alosdemos acadauno dos fesos ycadauno delodos un par de quantes mas dos pesos para las "chiringas enl eccasedil Convelso»

\$. 3. Hecho esto señalara el Rector eldia del primer acto auees el solemne yel del Farlícular aunquetambien puede ser publico dara parael los dos papeles díferentes doadiez y orho Comelusiones. las quales procurara que antes quese fijen enlas puertas de la Universidad condisposicion del Chanciller, Ael primer acto argumentaran quatro Bachilleres theoloţos seculares, O Religiosos Replicaran tres Maestros en Artes, o Doctores dela Universidad yafalta deellos los exsaminadores sinodales señalados porel Rector. Presidira aeslos actos el Macstro de Artes / _... Decano de la Universidad. o el Lector

(f. 230) de Arles del graduando aunque aya acavado deleer, oalguno de los Leclores de Theologiz andeasistir aestos actos deobligacion el secretario olos D.D. o M.M., señalados para juzGar dela suficiencia.

\$. 4. Concluidos estos actos señalara el Rector el dia del examen secrelo paraelrual adetomar elgraduando puntos en el texio da Aristoleles entres diferentes lugares de niano del Reclor asistienclo el chanciller yel secretario veinte $y$ quatro oras antes ysedara un tanto delos puntos ydel gue elijio el graduando alos exsaminadores paraque se prebengan. Cumplido el tiempo delas veinte $y$ quatro oras se juntaran el Rector el Chanciller, losdos leclores de theologia, yeldeArtes conotros tres Doctores de la taculiad para aprobar el acto y delos D.D. y M.M. del Claustro, los que hubiere queno oxcedan de doce todos los que asistieren pero la aprobacion la andedar solo siete, es- 


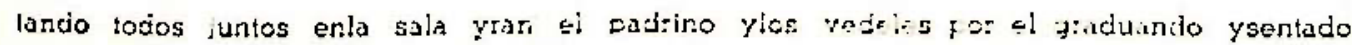

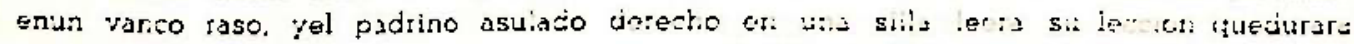

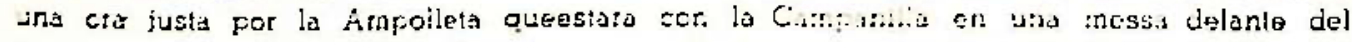

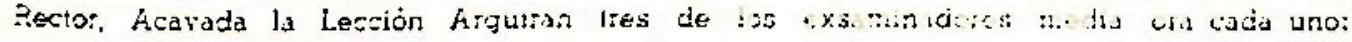

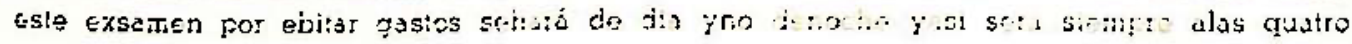
delatarde $=$

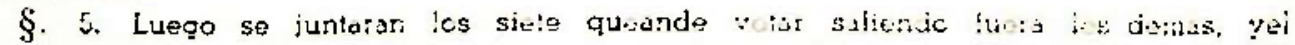

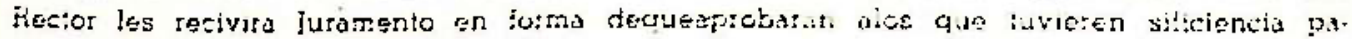

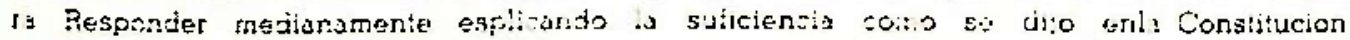

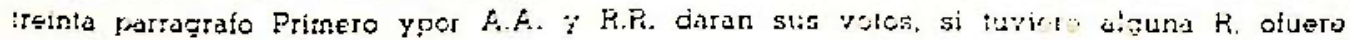

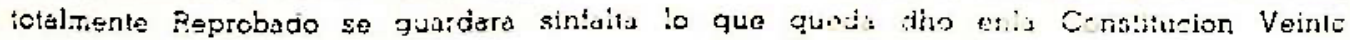

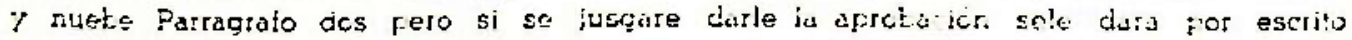

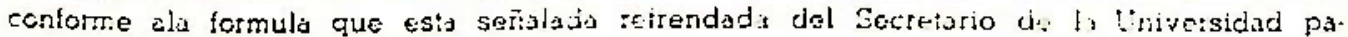
ta sue haga toe, Acarada la volocion sciara une tuen:e granie de Collacion murycr yequa iresca a los exsaminadores. Restci, y Chanciltot =.

§. 6. El dia siguiente despues del exsamen Serielo. reciviran fil giado sino Jo estorvare eniermedad. o causo lejitimis. lodos los D.J. 7 MA.M. tienen cbligacion de acompañar à! graduande sin insignias queno sellevan en Giado de Licenciado cu Arles $t i$

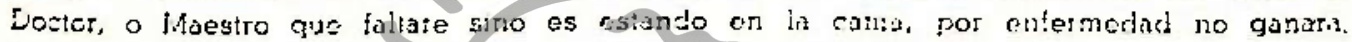

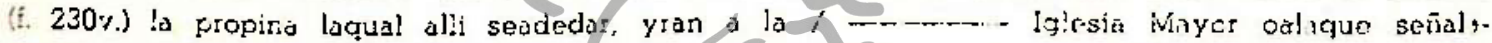
Ie su Illmme, o elquedicre el grade en cavido sede varante yulii ciara el grado yno

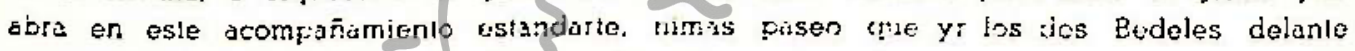
con sus mazas ylos demas de dos en dos $=$

\$. 7. Sentados todes se levanta el Maesito rius anijulio gueas el Decano en lu saculiad ycan el Graciuondo stllegara ai Graduarto yel Graduando pedira en lartin elcrädo de Licenciodo. yel fiecter mandará luego les pubijariente por el secrotanio la

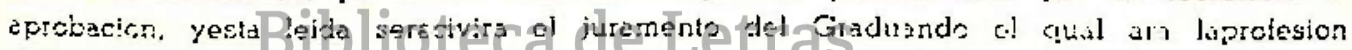
dela tes contorme a la forma quessia arajo y despues seledía a! grado en la forma

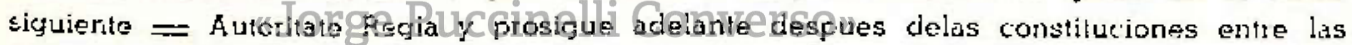
demas formulas delos gracias ylitules, Luego sedaran las ficpinas $y$ Guantos en salvillas ybolveran acompañundo al Licenciáda a su cirssa $=$

CONST. 36

\section{Del Grado de Maestro}

\$. 1. El que hubiere de Graduer cie Maesiro en Artes presentata sutilulo do Licenciado sino constare enla misma Universidad averlo recivido, algunos dias antes dopositura por dereches ala cjja doce pesos, al secretario ocho pesos, alos vedeles a cedauno quatro pesos, al Graduante ocho pesos, al padrino seis alos Maestros dela faculicd acadauno qualro pesos, alos Doctores quenoson delaficultacl acadauno dos pesos, yacaduuno detodos ellos un par de Cuantes y dos iibros de Collacion = para las chirimias yatavales quatrc pesos $=$

§. 2. El paseo se ara el mismo dia del grado yran los Ductores y Maestros con sus insignias de borla $y$ capirole los Maestros de color azul, los Doctores de Theologia de blanco los de Canones de verde, los de leyes de colcrado, los modicos de amari. 
Ito. los dos vedeles yran delante con sus mazas, el Graduando alo ullimo delacompañamiento entre los dos Doctores mas antiguos con capirole ysin bonete, despues ira el Chan-iiler y el Reclor a su lado derecho.

§. 3. Llegados al lugar del grado estara enuna messa una salvilla ysobreella el bonete ccn la borla azul y en olras dos salvillas las propinas empapeladas, subira ef Graduando con el Maestro decano de la facultad, ael asiento del Graduante, yalli lo pedira en latin brevemente yseledara el grado en la forma siguiente = Autoritale Regia \&. como so dira ael fin. Luedo se Repurten las propinas yol Recien graduado hace 13

CONS?!. 37

\section{Del Grado de Lizdo en Theologia}

§. 1. El graduando presentara sus titules de Backiller en theologia yprobara que arenido de pasante despues cue Recivio el grado de 3 achiller tres cursos deaseis messes yạue en el dho tiempo atenido libros deladha facultad Depositara los derechos deestegrado. que son ala caxa veinte y quatro pesos/ ael secretario doce pesos alos vedeles acada uno seis pesos al Graduante ocho pesos ael Padrino octo pesos a los Dociores de la facullad acadauno tres pesos, yalosquedeellos hubieren Arguido enlos exsamenes como se dira adelante un peso mas cada uno con que llevaran aquatro pesos, yacada uno detodoslos susodhos un par de Guanles ydos libras de Collacion, Paralas chirimias dos pesos =

\$. 2. Luego mandara el Reclor poner los edictos acostumbrados parasihubiere alqun Bachiller mas antiguo que quiera Gräduarse ypasado el termino sedara Luencia al Graduando para el primer aclo solemne elqual dara ocho dias antes las conclusiones que

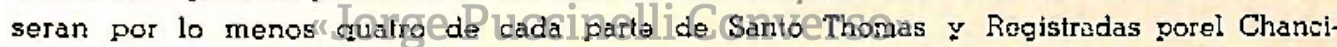
ller se fixara unacopiaenla puerta de las escuelas ysereparliran otras copjas alos Dcctores ylectores de theologia que señalare el Rector para exsaminardores.

§. 3. A este acto acudiran todos los Doslores y Maestros yenestando el Rector ylosdemas ensusasientos yran el Padrino con sus insignias ylos Beceles con sus ma. zas, por el sustenlante quesesentara en silla, los otros dos actos seran particulares concurriendo aello los Arquientes ylos que voluntariamenie quisieren delos Doclores y Maestros. peronotaltaran los queestubjesen señalados para dar el parecer dela suliciencia laqual adeser Ulira medioritatem, yenesta forma defendera el sustentante las questiones, y Respondera alas dificultades $=$

§. 4. Concluldos los tres actos señalarael Rector el día del exsamen secretoen. quese guardara la forma quesedio para Licenciado en Arles excepto lo sigulente. Primero que los punlos sean detomar enel maestro delas Senlencias con obligacion de relerir junlamente el titulo de Santo Thomas que corresponde a la misma materia / con sus partes proponiendo por lo menos la razon que trae el Santo Doclor; Sogundo que treinta oras anles dela Leccion yran por el Graduando y Padrino yantes de dar los puntos sedira la missa del espiritu Santo entre once y doce del dia enla capjlla de la Universidad estando el libro de los puntos sobre el attar yacavada la missa dara el Rector al Chanciller el lihro yabriendo enel portres partes sepondra un papel 


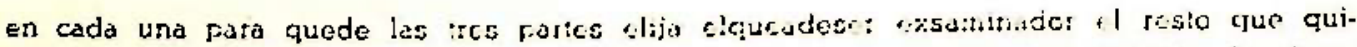

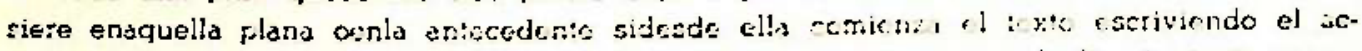

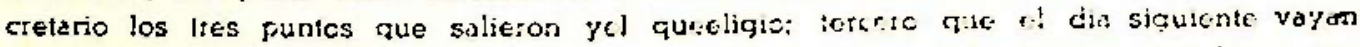
los vedeles a casa del Pedino yel traiga alaue adeser assemunado alas escuelas y vo rido seentacta arecapacltar si Leccicn hasta que lo azisen: quatro que sentuclo el Reo to: Chanciller $y$ exsatninadere calo eal- dispuesta putacsto seleverntata el Padtino accrsper̂ado de los Bejeles con stis mazas ytrora je! arijucio que scritudo en vanco Rasso hechaia veria yel padrino asulade sentado en silla lecra lnid or entera for ampolle-

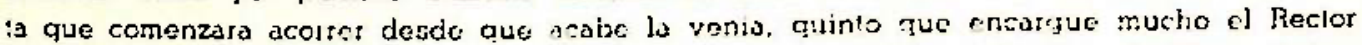
¿los que exsaminan $\gamma$ Arguien tue lohagan contodaexaccion, sidespues doellos quisisre el Chaneller, o algun Doctor tci..tr to mano y Arquir podrn contal quenc pasén de sels los Argumentos. Acavado el exsamen sedaran a los exsaminadores $y$ padrino las propinas señaladas, seprehendran dos telus de cera deadoce onzas forsillegare la noche. ytres fuentes buenas de colacicn mayor. Y aqua adrezada póa que tomen un refresco el Rector, ehanciller, exsaminadores. yelsectelario.

§. 5. Darael Rector a cada uno de los exsuminadores dos Letrás de plata, una A. $\gamma$ una R. yen una cujita queeste dedicada poraesto hechara ia Letra que jusgare tiene obligacion enla parte donde esta señalada la A. . y la letra que le sobrare hechara enla division que tiene la dha cajila para que no sepueda conccer for lo letra que sobrate quien hecho Lì A ola B. ysiel numero delas R.R. excediere se negara cl grado.

(I. 232) silubiete alguna $R$, seracon / - el loque se dixoenla constilucion veinte y nuebé, Parragarlo dos $y$ constitucion ireinta $y$ cinco Parragralo cinco, siexceden las A.A. sedarala aprobacion tirmader del chanciller y Rector $=$

§. 6. El dia siquiente irael Padrino yel Decano dela facultad acasa del ahijado. Ylo traeran a la Universidad donde se juntaran todos los Doctores y Maestros con sus insignias ydesde alli iran èn forma de Universjoad apie precediendo los vedeles consus inazas tomando el paseo for lo plaza del logar donde-seade dar el grado que sera en la nabe dela Cathedral derase del Choro.odonde oseñalare cl, graduante ysedara el grado. haviendo hecho la profesion de la fee. segun la formula que sea punto en la Constilucion treinta $y$ cinco. Partagrafo siele ysepondra enteramente al fin de estas constituciones, solo que se añadira ut cum volveris possis ad Gadum Docloratus ascendere sereparliran las propinas enel teatro del gual bolveran acompañando al Licenciado asu Cassa $=$

CONST. 38

\section{Del Grado de Dr, en theologla}

§. El que prelendiere Graduarse de Doctor ccurra con su peticion ael Fector en que se presenle para el Gradoel Rector hara juntar el Claustro y quedelanie del se presente y exsiva el titulo quetiene de Licenciado con leslimonio del Secretario deque tiene depositados los derechos del grado que seran ala caja Veinte y quatro pesos, ael secrelatio Doce pesos, ael Padrino o Decano de la facultad doce pesos alos Doctores do la tacultad aocho pesos alos que no fueren de la lacullad aquatro pesos, aelque diera el vejamen veinte pesos, al Graduante ocho pescs acadauno deellos, un par de Guantes ydos libras decollacion alos vedeles acadauno ocho pesos, yalas chírimias yatabales quatro resos. $=$ 
\$. 2. Luego severa enel libro delos grados sitiene penitencia alguna ysilatiene so aboriguara sila acumplido. Y verificado quepuede Doctorarse se mandara poner ediclos contermino de quince dias o menos ajuicio / del Rector para que sihubiere Licenciado

(F. 232. v.) mas antiguo paresca a presentarse, yRecibir primero el grado y siel dho Licenciado pretendiere Gradurrse antes de pasar ai cho termino, seaconcargo quesidentro del sepre. senture otro mars antiguo sele ade guardar el derecho de antiguedad.

$\$$. 3. Latarcie antes del grado serael paseo del Dotorando encuya cassa sepondta o! estandarte dela Universidad que auna vanda lleva las Armas deella yalaotra las del Docic:ando que ara asucosta en un tafetan y se pondra un escudo enunbastidor ala puer!a de su curssa sobre un Dosel con sus Armas, yran paraeste paseo todos los Doctores, yMaestros acavallo acasa del Doctorando yelque faltare aquella tarde perdera la mitad de la propina; y si faltare el dia laperdera por entero, sino estubiere enfermo enla cama, saldran los atavales, chirimias, yvedeles con sus Ropas y mazas, Luego el acompañamiento de Collegiales y seglares, luego el estandarte ytras el secretario. los Maestros, y Doctores conborlas ycapirotes puestos, el ultimo sera el Doctorando queyra entre el Doctor mas antiguo yel Padrino sin Bonete yelcapirote no pues!o sino sobre el ombro izquie:do yasidaran buolta alas cal!es mas principales delaciudad.

§. 4. Parael dia siguiente seade hacer un tablado a costa del Doctorando enla nave detras del choro delacathedral, oenel Patio dela Universidad odonde el Señor Obispo quisiere darel grado yadeser deunstado de alto, ycapaz queenel quepan todos los Doctores, y Maestros, yenmedio del asiento ala parte donde seade sentar el Graduante enlo alto sobre la colgadura estaran las Armas Reales y Pontificias, enel izquierdo las dela Universidad abajo, aelderecho lasdel Señor Obispo, odelquediere el grado, yabajo las del Graduando, junto al asiento del Señor Obispo, odel Graduante estara una messa con las insignias Doctorales, yconlas fuentes delas propinas yun taburete Rasso junto aella para el secretario.

§. 5. Si sucediere queel que sequisiere Graduarse Combidare ael Cavildo secular yra el estandarte dela Universidad enel paseo delante del cavildo, y Univer/sidad. Las

(F. 233) Mazas del cavildo. Qdele Universidad yran en Vala Snterpoladas detras del estandarte y inmediatamente yran los dos maestros menos antiguos luego iran los del cavildo ylos de la Universidad entreberados conbuen orden de forma quenotodos los deun Gremio vayan al lado derecho, nial izquierdo, el Rector ira en medio yasulado derecho al correjidor ael izquierdo el Chanciller tendran los del cavildo secular su asiento enfrente de donde sesentare laUniversidad, ysedara a los del cavildo dela ciudad acadauno una par de Guantes ydos libras de Colacion yno propina deplata, sino es que el Doctorando la quisiere dar desu voluntad, yenese caso sera como a Doctores de otra facultad, llevara el estandarte la persona aquien lo encargare el Rector Doctor de la Universidad, ode cavildo secular ysiendo Doctor elquelolleva, llevaran las Borlas dos del cavildo secular, ysielquelo lleva esdel cavildo secular, llevaran las Borlas dos Doctores yporsu falta dos Maestros dandose el grado enla Iglesia sesentaran todos envancas solo el Rector yelque diere el grado tendran sillas.

§. 6. Siaconteciere que el que segraduare combidare al cavildo eclesiastico yra enel paseo delamisma forma que el cavildo secular interpelandose con buen orden. $Y$ se sentaran despues enel tablado con la Universidad interpolados conlos Doctores yseles 


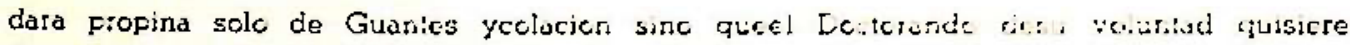
deries P:ofuna como a Dactercs deotra focultoj.

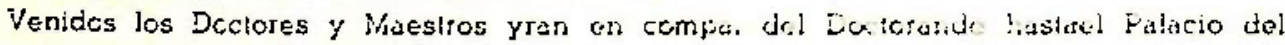
Señor Obisfo questa continuo ala iglesia yhaviendo ccrictudo su berionja ciro dar el

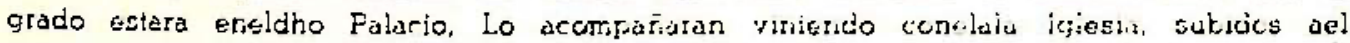
tablado, el Decano dela tacultad, cel Pacitino subiro utra Calhedra quetisis enun icdo dei teato ydeaili proporía una question peraquela Dispulo of Doctorando pro utraque pòre sin fundaria ni Disputar ia Trus cue proponeriá en latin en breves y elcganles Fazones sin hacer oracion entonces $e$ ] Doslc:ando / arnmudo ula Callodra en fio y junto

(F. 233 \%) ael los vedeles con sus mazas Dispulata krevemente hasta quecl fecter le haga señal cen la campanilla mandandole callar, enacavando yran los vedeles cesde la Calhedra con e! Fadrino $;$ le senlaran despis del Rector orta mano izquierda del Graduante porque sesuponeque el asiento dol Recer es inmediato ael del que di el Grado como Cavezà quees dela Universidad, sentarase entonces el Graduando enlaburete deespaldar sies enla Iglesia zsino es enella sesentara ensilla junlo ala messa, $y$ luego subira ala Cáthedra el Doclor o Maestro mas moderno ydaracl veiamen cuedurara por lo menos media cra, Pero se odvierte gueantes tuve se tome dememcriar sriade Registrar conel Rezlo: o con otujen el Rector señalare perqus nase daga enel cosa que no combenga. Y lo mismo se ara en las Cedulas que suelen leerse y si despucs desto se añadiere alge sin dar parte al Recicr perdera elquedes vejamen la mitad delapropina irrelragablemente.

§. 7. Acavado el vejamen iran los vedeles äcl asienio del Padrino yle traeren ala messa y cojiendo al Graduando asulado lopondra en pie delante desu seioria odelque ensu nombre ode cavildo sede vocente diere el grado; alli pedira el grado en blen Jatin con un parrafo Breve. aquerespondera su sentencia alguno de los Doctores mas cercanos oaquien sele cometiere con olra oracion breve tambien Lalina en loor del mismo Dolorondo. A.cavada esta se incara de Rodillas Cel Daforando ante.su señoria yel Rector lo recivira juramento puestas las manos enurmisal conlorme ala formula queesta abajo Acovado de hacarse el juramento se traera de la messo el bonele con la Borla, y seledarael grado por su Señoria en la forma que aqui seopunla I despues se pondra enteramenle, Autorila14 Regia \&.

§. 8. Luego se incara de Rodillas el Graduando delúnle del Reclor quela dara las Insignias Doctorales haviendose puesto el Capirote enesta forma.

Lo primero le dara el osculo en un carrillo diciendo accipe osculum pacis in signum fraternilatis el amititie.

Lo segundo lepondra elanillo enel dedo Díciendo / Accipe annulum aureum in signum coniungii inlexte el sapienliam lanquam sponsam charisiman.

Lo lercero le data el Libro diciendo. accipe Librum Sapientie ul possis Libere et mubilie alios doceri; yacavado de dar el grado vendra el Padrino con el nuebo Doctor aque abrace al Graduanle yalcs Doctores y Maesiros primeroo los de la mano de. recha, ylueço alos de la izquierda del Graduante yentrelanto se Repartiron las propinas. 
CCNST. 39.

De los asientos

§. 1. En tcdos los actos Publicos de Universidad asistiendo el Sr. oblspo tendra susitial delante. yallado derecho al Rector, yal izquierdo ael Chanciller en sillas y luego scseguiran por un lado, yporotro los Doctores, y Maestros enbancas ensemejantes casecs, actos secretos, publicos y exsamenes nose ade dar asiento apersonas queno sea Doctor. Maestro. oCathearatico deesla Universidad Aunque sea Doctor, o Maestro, porotra otenga quaiquier oficio ocarģo desumagestad sino fuere obispo otogado, yenesto no devg aver dispensacion alguna enlotocante alos asientos del cavildo eclesiastico ysecular, esta determinado enla constitución treinta y ocho Parragrafo, cinco, yseis yenelmodo desentarse quardaran la antiguedad desus grados sinque entre theologos y juristas aia proheminencia ni diferencia alguna, pero precederan todos los Doctores, a los Maestros en Artes, aunqueestos sean mas antiguos.

§. 2. El secretario tendra asientoenel Claustro enun banco dentro junto ala messa queestara aunlado yenlos actos publicos enun taburete iunto ala Cathedra yenlos paseos el primero conlos Maestros los vedeles en banco Rasso, escaño alo ultimo detodos cada uno asu lado el tiempo del vejamen estaran sentados, alo demas enpie, quando se hace Claustro de negocios secretos estaran los vedeles enla puerta como porteros alaparte de afuera yentraran enhaciendoles señal con la campanilla.

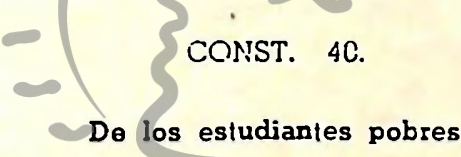

\$. 1. Si los que se hubieren de Graduar entodos grados fueren tan pobres queno puedan pagar las propinas por entero las moderara el Claustro conforme aala posibilidad constando / de la penuria comoise observa en las Universidades deespaña porque la

(F. 234 v.) intencion Real ylanuestra es de favorecer a los pobres que no pueden Recivir el premio de sus estudios por no tener con que irse a Graduar ala Univrsidad de Lima o aotras, alos collegiales desan christoval que sirven ala Cathedral de Guamanga, seles perdonara la tercera parte de las propinas y lo mesmo se les perdonare alos collegiales del Seminario deSan Antonio Abad del Cuzco que vinieren a graduarse aesta Universidad.

CONST. 41.

\section{De la educacion do los estudiantes}

§. 1. Entiendan los estudiantes de facultad deestos estudios queande dat entodas cosas buen exemplo yqueno les corre menor obligacion enesta parte quealos de latinidad haciendo sus confesiones, comuniones ydemas actos de virtud.

\$. 2. Antes o despues de Leccion oiran misa con devocion ysilencio excepto liss collegiales queguardaran el orden de sus Constituciones queles emos dado.

§. 3. Todos tendran gran cuydado nosolo de asistir alas Lecciones sino aqualquier exercicios Literarios, conferencias, conclusiones, ysavatinas yactos quando los señalaten paraellos yentodo se portaran con gran silencio quietud yobediencia al Rector. 


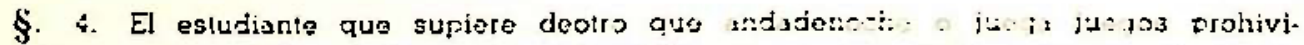

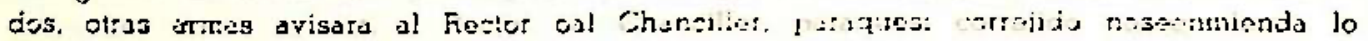
hechen do los esiudics.

CONS: 42

\section{De las Incorporacionos}

§. 1. Acimilanse a incorporarse eneste Universtdad los que hubieron sido Graduados enlas Universidades de Salamanca. Altala de Henores, Vallodolid. Grafiadi. Sevilla, Osuna ydelas Indias solo lade Lims y Ḿexico.

§. 2. Y sialqunoz Graduados de Dostor, o otros Grados en Chuquis.sca. Quito, Cuzco, o Smliago de Chile yotras intentaren incorporarse enest. Universidad de Guamanga no sean admitidos. Pero trayendo sus lestimonios fidedirgnos autorizados ytitulos sepuedan admitir a exsamenes Rigurosos de Bachilieres, Linenciodos. $y$ M. M. en Artes, Bachilleres, Licenciados. 7 Doctores en Theologita como si huijeran sido cursunles enestu Universidad y saliendo aprobados por A.A. Y R.F. contodes los votos $\sin R$ alguna fodran recivir los dhos grados. Y sisucaren alguns R. seran escluidos / yla mismi formi

(F. 235) soguardara conlos Religiosos que se hubjeren de graduat oineorporar como esta digpuosto en laconstitucion sjete Parragrato dos; con los collegiales desan Antoriso Abad del Cuzzo que vinieren con testimonios fidedignos del Rector ycalhedraticos de aver curgado ensu collegio cumplidamente otros lantos cursos como serrequieren enesta Universidad pagendo los Unos, ylos olros las propinas ccmo esta orcienado.

§. 3. Para la incorporacion de los dhos qrados de Unjersidades de Limu. Mexico rdeEspaña saande presentar los fitulos portestimonio autentico decllos yla incorporacion seadehacer por Claustro y siendo la mayor parle de pareser quesereciva serdmitira aincorporar dando detodos los derechos que avia de pagar sino fuera graduado los dos tercios yasi deposilaria el Mãestro en Artes. para la caja ocho pesos, ael socretario sols pesos, alos vedeles acadauno dos pesos. alos queno sor dela faculiad aunpeso yatodos una par de Guanies, «el DoztorPenceinones iotheologiancontribuyra ala caja Diez yseis pesos, aelsecretario ocho pesos alos vedeles acaduno aquatro pesos, asu señoria oalquo estubiero ensulugar ocho pesos. alos Doctores icadauno seis pesos, alos Maesiros acada uno, atres pesos, yacadauno de lodes un par de guanles $y$ dos libras de collacion paraeslas incorporaciones no aypaseo sino de Recivirse enel Claustro, Pero sianla $\propto$ casion se graduaren olros saldran conellos los que se incorporaren junlos enel paseo $\gamma$ roci. viran vejamon.

CONST. 43.

\section{De lo Polestad del Señor Oblapo}

§. 1. El Señor Obispo que por tiempo fuere como sucesor del fundador y inlerosado enel lustre deesla Universidad de donde seande criar sujetos que ayuden ades. cursar su conciencia como consejero desu mageslad ade amparar aesla Universidad, velando scbre ella yqueno sequebranien sus Constitucioneg enla menor circunstancia porqueno descaszea delcredilo, adeser su Director ydefensor, adedar los grados como 
esla cicho, y porsuimpedimento, ozusencia adenombrar persona de autoridad yconciencia queloscie: ypara no multiplicar ministros sera aproposito el chanciller queasi mismo to sera el Provisor conque tendran premio las letras yla virtud.

§. 2. Esperamos quelos señores obispos iran fundando Cathedras deCanones y leyes queconque cadauno funde una llegara esta Universidad al lustre que sepueda desear.

§. 3. Y porque esta fundacion seaecho por instrumento publico ante Francisco blanco cscrivano publico y cavildo dela ciudad de Guamanga este año de mil y seir cientos y setenta ysiete de laqual seapuesto un trasumpto autorizado enelCamarin / y

(F. 235 v.) secretaria de nuestras Cassas enel Libro Primero de Bullas y Cedulas Reales nopermitira suseñoria porel exemplar delos papeles yprotocolos quese pierden deordinario enesta ciudad salga dela secretaria el dho trasumpto.

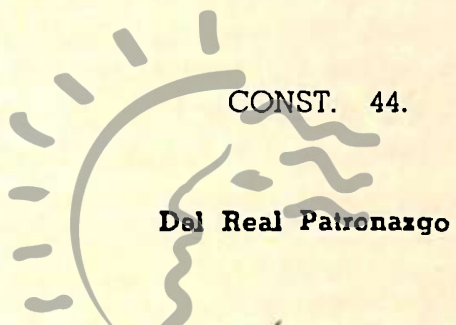

§. 1. Paraque floresca esta Universidad confirme estabilidad enservicio del Rey Nuestro Señor ybien de sus vasallos enestas Provincias Remotas. Y enlas deeste obispado de havitadores pobres ynecesitados que no tienen sustancia parair abuscar Letras aotras Universidades ypor ser esta Ciudad Barata ydebuen demple sin divirtimientos yporello aproposito para estudjos generales isuplicael fundador al Rey nuestro señor la confirme yla Reciva enla Protección y Patronato Real enquedesde luego lapone despachandole Cedula Rl admitiendola yconfirmando estas Constituciones mandando que como las Universidades de opinion los sujetos deesta Graduarlos de Doctor o Licenciado sean admitidos alas oposiciones de canongias yotras Dignidades entodas las Iglesias cathedrales del Dominio desumagestad, ya incorporacion enlas Universidades insignes dela Constitucion quarenta y dos, encargando alos Virreyes del Peru hagan pagar la Renta delas Cathedras, sihubiere omision yla indemnidad desta Universidad como prenda del Patronato Real yque cuyde encada diez años yantes sila necesidad lopidiere denombrar Visitador para ver como se cumplen las constituciones ysepagan las cathedras acosta de culpados yapedimento delas propinas que hubieren percivido deque resultare elservicio de àmbas magestades. 
Formula de dar Grado de Br. en Arroe

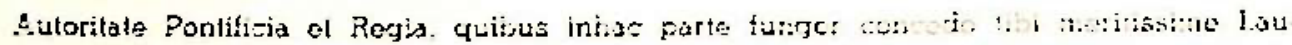

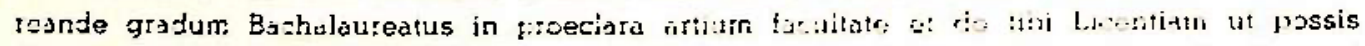

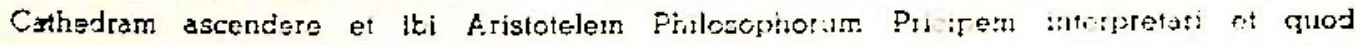

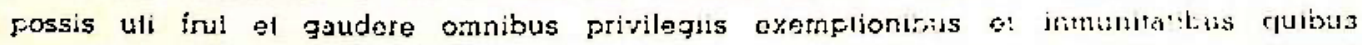
potiuntur el gandent omnes simili graducondeccratt in Selamirlicenst at Limont rlisqui Requs Universitatibus secundum Bullos aprostoneas guosige bulus rrodi grarlus libi

(f. 236) ubique loccrun sulfragentut, ouod / tibl tolix faustun: nus at in notiae Pitris et fily et spiritus Banti Amer.

\section{Formula de dar Grado do Lizdo en Artes}

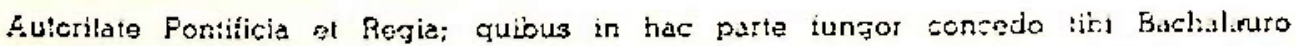
reritissimo gradum ticentiatus ut cum e Pectore e! Charcelario studiurum Universitatis tueris aprobalus juxta Eullas sppostolicas et scodulas Regios possis cum volveris ad Gradum Magistraterii inpreclara artium facubtire ascerndere al concedo libi omnis privalegia imunilatis et exempliones. qubus petiuntur el gaurlent gur sinitcmi gradum adempti sunt in Salemanticensi Limeni aliis que Reguis Unizersilatibus quodque huils modi tibi ubjqui Lccorum sufragretir in nomine Patriz at fily et spiritus sancti Amen.

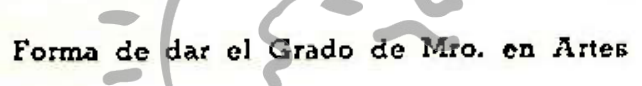

Autoritate Pontilicia et Regie quibus in has patle iungor consecio tibi Licenciato meritissimo gradum Magislerii irnproclara artium furulale per inpositıonem huius pillei et concedo tibi omnia privilegia inmunitates ot exempliones quibus potiunlur et qaudent aui similem gradum adempti sunt in Salamanticensi et Limana a allisque Regis Universitalibus innominine Patris et tily CeC Spiritus saneli Amen.

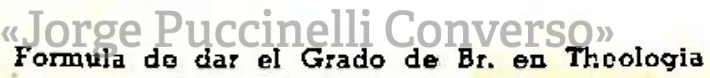

Autoritate Pontificia et Regia quibus in hac parte furgor concedo tibi meritissime Lau. reando gradum Bachalaureatus in Sacro teologie facultate et do tibi Licentiam ut possis Calhedram ascendere el ibi Magisirum Sentenciarum interpretari et quod possis uli fruir et grudere omnibus privilegiis et exemplionibus quibus potiunlur el gaudent omnes simili gradu Condecorati in Salamanlicensi el Limana aliisque Regiis Universitatibus 'secundum Bullas Appostolicas et scedulas Regias quodque huius modi gradus tibi ubique Locarum: (f. 236v.) sufragretur quodibi felix faustumque Sil, in nomine Patris et fily et Spiritu Sancli Aemn. /

\section{Formula del Grado de Lizdo en Theologia}

Autoritate Pontificia el Regia quibus in hac parle fungor concedo thbi Bachalaure merilissime gradum Licenciatus ul cum a Rectore et Chancelario sturiorum Universitatis fueris aprobatus iuxla Bullas Apposlolicas el scedulas Regias possis cum volveris ad gradum Doctoratus ascendere et concedo tibi omnia privilegia el inmunitates quibus potiuntur et gandent qui similem gradum adempti sunt in Salamanticensi of Limana 
uilisque Fogus Universilatibus quod que huius modi gradus tibi ubique Locorum sulraqetur inomine Patris el fily et Spirilus Sancti Amen.

\title{
Formula del Grado de Dr. en Theologia
}

\author{
porte
}

Sutoratila Ponlificia el Regia, quibus in haclungor concedo tibi Licenciæa meritissimo Gradum Doctoratus in Sacre teologia facultatte per impossitionem hujus pilei el concejo tibi omsia privilegia inmunitates et exemptionos ouibus potiuntur el gaudent qui similen gradun adempti sunt, in Salamanticensi, Limana, aliisqui Regis Universitatibus inomina Patris et fity et Spiritus sancti Amen.

\section{Formula juramenli Doctonm Graduan dorum el eorum qui in hanc Universitatem volunt incorporari}

Ego N. juro Sancta evengelia Corporaliter perme lacta, quod in negotis Universitalis et factis consilium, auxilium et favorem fideliter prestabo el curabo, diligenter ut quantumisine est Bullas Appcstolicas et Scedulas Reglas huius Universitatis quod omnia que in ipsis continentur circa fancultatem dalum ad aprobandum at gradus et llimo. D. Episcopo Guamanqensi. Vel Capitulo sede vacante huius Cathedralis Eclesie ad lesdem gradus conferendos suam habent inlegram et expeditam executionem: iten quoad vocationem Rectoris predicte Univesilatis veniam toties quoties per ipsum fuero requisilus neque ero in Consilio adversus Constituciones et Staluts predicte Universilatis sicme Deus adituet hec Sancta Dei Evangelía. /

Formula iuramenti Delendende Purissime conceptionis Beate $V$. Maris quod emittendum est Bachaleureis in theologia Licencialis in Philosophia et Dociorius in Theologia

Ego N. Orinipotenti Deo Virginis filii at que jpsi sanclissime Dei pare que Mater sapienti Gentium Magistrmmoruzl Cisdiplinal coramVRdos Cadmodum huius Universitatis Guamanguensis Sancti Christhophosi Rectore ae Ceteris Dominus Doctoribus ac Margistris promito ac sancte. Juro per hec ipsa Sancla qualuor evangelia per me corporaliter tacta me iuxla pium ac Baudabili huius Universitatis statutum. quod tirmun perpelum que torecupio ac volo semper et ubique proflesurum, Docturum, defensurum; neque uirquam aliter verbo aut scripto aut quacumque alic ratione acturum, veramiliam, ac naturalem sunctissime Virginis conceptio nem in primo ipsso vite initio omni prorsus originali Labe causse quipe quam in nullo um quam lemporis momento primi Parentis primum peccatum attigit quod quantum mihi per Eclessie Catholica et Sanctissimorum Pontificum Sanctiones Licet toto corde profiteor ac credo; alque ad Dei et Virginis Matris, gloriam. Sapiente Splendorum huius Academie ornamentum et anime mee salutem proseculurum Spero.

\section{Protessio Ildei}

Ego N. firma fide Credo et profiteor omnia el singula que continentur in simbolo fidot quo sancla Romena Eclesia ulitur videlicet, credo in Unum Deum Patrem omnipo. lentem factorem celi el Terre Visibilium omnium et invisibilium et in unum Dominum fesuchristum filium Dei unigenitun, el ex Patro natum ante omnia secula Deum de Deo, Lumon de Lumine. Deum vorum de Deo Vo Ro genitum non factum con substantialem Patri 


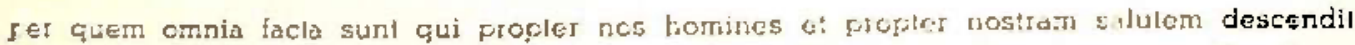

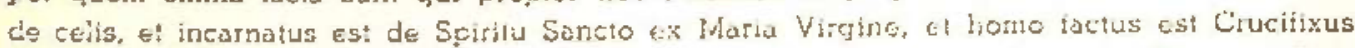
eliam pro notis sui Pontio Pilato cassus ol sepultus esl resurrezil letria die secundium scripluras et ascendil in celum: Sedel ad dexieran Patris ilicium veniurus est cum gloria jujicare vives et mortucs / cuyus Regti ncn eril tinjs: e: it Spiritum Sanclum Lomino el vivificantem, qui ex patre filio que procedit qui cumpatre at filio simuladoratur et cunglorificalur auj Locutus est per Frophelirs et unam äctam cutiolicam el aposiolicam eclesiam: Confiteor unum Baptisma, in rrmissionem pecalcrum, ei specto Resurtectionemjuctucrum, et rilam vanturi seculi $\mathrm{hmen.} \mathrm{Appostolicos} \mathrm{el} \mathrm{ecclesiasticas} \mathrm{traditiones,}$ reliquas aue elusdem Extesia osservationgs, et constituciones frmissime admillo et amsisctcr, fiem sacram scripturam iuxla um sensum quem lenuit et tenel sancte mater Eclessia cujus est judicare de vero sensu el interpretatione secrarum scriplurarum admito, nec cär.um quam nissi iuxte unanimen sensun fürum icristam, eil interptotabor Prolileor çucque septecesse vera et propie sacram anla ncve Legis ajesuchrislo Domino nosito instíluta adoue ad salutem huriani generis, Licel non omnia singulis necesaria scilicet Eaptismun, confirmationem, euchuristicor, Pententiam, Exiremauntionem ordinem et matrimo. nium, illaque gratiam conferre, ef exhis Baptismum. Conimmationem, et ordinem sile sacrilsgio reileraninon posee Receplos qucque el aprobalos eclesie Catholice ritus in supradictorum: omnium sactamentorum solemni adminislralione recipio, el admitlo omnia Elt sincula que depeccato oríginali, et de justificarione in Sacro Sancta Tridentina Sinodo definile et declarata fuerunt amplecior, et tecipio. Proliteor puriter in missa oforri Deo verum fropium elt propitialorium sacrificium pro vivis el defunclis, at que in Sanctissimo eucharistie sacramento, esse vere realiter, et Corpus et sanguinem dna cum anima et divinilate Domini Mostrijesuchristi lierique conversionem tolius subslantie panis in Corpus el totius substantie vini in sanguinem quam conversionem cálholica eclesiä transubsiartiatenem apellal. falecr eliam subaliera tantum specie tolum àt que integrum chrislum vercumque sacramentum sumi constanler teneo Purgatorium esse animas que ibi detentas fidelium su ffragiis jubari, similiter etl, sanctcs una cum christo reynantes venerandos, atque invocandos esse eosque brafiones Deo pronbbis oferre atque eorum reliquias esso venerandas fimissimi asero imagines christi ac Dei pare Semper Virginis, nec non aliorumsanlorum habendas el relinendas / esse al que eis devitum honorem, ac venera(F. 238) tionem in pertiendam, indulgentiarum eliam polestatem e christo in ecclesia reliclum, lican et appostolicam Romanam eclesiam omnium ecclesiarum matrem. el magistram ag. nosco, Romano que, Ponlifici Bealj Petri Appostolorum Principis sucesori ac jesuchristi vicario veram obedientiam Spondeo. ac juro Cetera ilen onnia a Sacris Canonibus el cecumenicis Concilis ac presipue a Sacro Sancia lidentina sinodo tradita, definila el declarata indubitanter recipio alque proliteor: simulgue contrarie omnia alque hereses quascumque ab Eclesia damnatas el rejectas, el anathematizádas, ego poriter damno relicio el anathemalizo: hanc veram catholicam fidem exlraquam nemo potest salvus esse quam inpresenti sponte profiteor elt veracjer teneo, eandem inlegran el inviolatam usque ad exiremum vile spititum conslantissime Deo adjubante relinere et confileri atque ameis subdilis vel illisquorum cura adme inmunere meo sepeclabit, teneri Doceri el predicari quantum inme erit curaturum ego idem N. Spondeo. Voveo, ac juro, sic me Deus aduibet, et hec sancta Dei evangelia. 
Prosigue la tundación y Donazion

(F. 238 v.)

Y en contormidad de la dhas constitucjones yordenansas desuso insertas yponiendo en exezucion nuestro buen deseo y para que tengan efecto desde Luego enaquella mejor via ylorma que podemos y a lugarde derecho ycomo cjertos ysavedores que somos del nuestro ydeloque eneste casso nos combiene hacer denuestralibre yespontanea voluniad Ynsiluymos fundamos, erifimos, ycriamos ad Perpetuam Rey Memoriam la dha Universidad ennuestro collegio seminario de San Christoval desta Ciudad de Guamanga delas Frovincias del Pers para rguenel segun las dhas Constituciones seestudien portodas aquellas Personas que quisieren aplicarse a las letras de qualesquier parles que sean las facultades de Artes y 'Theologia que enellas se expresan Guardandose sutenor y forma sinaue oxceda deellas en rosa alquna, ypara que entodo thempo Permanesca firne. yconstante la diha Universidad ylos Cathedraticos queande leerlas señaladas en ellas tengan efectivamente lacantidad depesos que / les aplicamos acada uno en dhas Constituciones para su congrua sustentacion yque con esso acuda cada uno aloque deve con el cuydado y viggilencia que deven yson obligados, Hacemos Gracia y Donacion aladha Universidad. pura merra, perfecta, acavada eynrrebocable queel derecho llama interbivos del Palacio $y$ cassas episcopales queestan conjuntas eynmediatas a nuestra iglesia cathedral y juntamente de los alquileres yarrendemientos de catorce tiendas que deellas salen a la calle $y$ de $\mathrm{l} x$, dela notariamayor queesta enel zaguan de dha cassa laqual estoda obra de cal, y canto fabricada y pagada toda ella denuestro patrimonio desde sus cimisnlos segun se contiene enla Consljtucion Diezz y seis delas aqui incertas. Y asi mismo dei conso deías mill pesos de principal expresado enella paraquetodo ello sea desde oy dia delafecha deesta fundación enadelante perpetuamente ypara siempre jamas dela dha Universidad $y$ sean como tales vienes $y$ Rentas suyas propias paraefecto depaqar las situcrdas enellas las dhas Cathedras, plodemas ocontenido en dhas constituciones porque asi es mestra voluntad, ypara que seguarde ycumpla entodo y por todo ylleven adevida execucion conefecto yqueno seexcecia deellas encosa alguna, dsde Luego para que quando llegue el casso nos desistimos, auitamos, yapertamos, del derecho, yacrión, propiedad, señozio y posesion queernos tenido ytenemos alas dhas cassas ypalacis episcopal yalo enallabrado y edificado yal principăl del censo delos un mill pesos referidos desuso para que como dho es "seatodo ella pfrthpopios qRentas dela" dha Universidad yatectos aella para la pagas desus cathedraticos que fueren de ella ydemas electos aqui expecificados ysepusdan aver $y$ cobrar sus arrendamientos yalquileres assi delos señores oíispos nuestros subcesores que portiempo fueren como delos inquilinos que ocuparen dhar tiendas ydemas personas que havitaren dha cassa exsede vacante ydelos posehedores que fueren delas casas sobro queesta impuesto el principal del censo delos / dhos un mil

(F. 239) pesos quepara quelopueda hacer otorgamos en favor dela dha Universidad ydequien porella fuere parle esta escriplura de Donacion firmisima por la qual osutraslado autorizado en pública forma y manera que haga fee haviendo precedido la aprobación que abajo yra declarada ledamos todo nuestro poder cumplido quan bastante dederecho serrequlere yesnecesario paraque porsu autoridad o judicjalmente como le pareciere el Rector que fuere dela dha Universidad oquien porella fuere parle lexitima pueda tomar yaprehender latenencia yposesion delodo lorrelerido que paraello le ponemos y constituimos procurador aclor como ensu mismo tho $\mathrm{y}$ causa propia yenel interior quelatoma nos constituymos porsu inquilino tenedor yprecario posehedor para seladar cada vez $\gamma$ quando que porsuparte nos fuere pedida yenseñal deella yde verdadera tradicion le olorgagamos estaescriptura de Donacion enforma paraqueporella la pueda tomar yaprehender sir otro acto deaprehension alguno, ypara que sumayor parpetuilad. Yque floresca la 


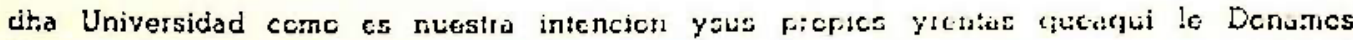
Damos yseñalames de nuestro Patrimonio como dhe es siempie vayan cn aumento yno vengan en Disminucion desde luegean quanio codemos hascmos y Damos esla Donacion for insinuada, y lexitamente manifestado anle juez conipetente slaqual redinios y encargamosla apruebe $y$ Ratifique entedo $y$ for lodo segun quecnella se expresa unnque exceda delos quinientes sueldes quelaley Reul disfonc quesein las Donaciones porque del tal exceso. demissia. cmas valor es nuesira voluntad de hacer como hacemos asi mismo aladha Universidad para los efeclos, Referidos Gratia y donacion sin limilacion ni crdenalguna la qual hacemos for las causas y motibos aqui declarados sin que aello nos tiueba otra causa alguna mas quael servirio deambas Marjeslades. encuya consideracion promslemos ynos obligamos deno retocar / Recismar ni contradecir esta fundacion

(F. $239 \because$, $y$ Donscion que hacemos dora nientiempo alguro por ninguna causa in razon que sea. portestamento. Cobdicilo ni porotro instrumento alguno nitampcco pordecir que fue inmensa. niporotra dolas conves queel de:echo disçone cuenos compclan, opucdan compeler lacita oexpresamenle porque declaramos çuefara hacería yo:orgarlo ancs lenido el acuerdo $y$ delibetccion queen semc 'ante casso sempquiere, y sila lal Revocacion hicierenos, desde lnezo la damos for nuls y Jeninợun valor niefeclo para que no valga ni haga a!fe en juicio ni fuera del, ni se haga meneion ni casso de ella, como sino se hubjese focho, ni otorgado, antes porel mismo hecho queademas firme y valida esla funclacion y Donacion auelacemos enella adha Unversidad, perpetuamenle ypara siempre jamas, por los molibos y Pazones aqui inclaradas ylohacemos demas deloneferido contadas las clausulas, vinculos, yfirniezas queparasu validacion serrequieran ysean necesarias dederecho aunque aqui nose expresen yospecial mencion deellas se haga enestaescriptura las quales Damos for expresadas, entendidas. ycomprehendidas enella fata nonos aprovechar, ni valer deellas aora nien tiempo alguno sino que siempre yentodo acontecimiento permanezca youede firme yvalida como enellase contiene ydeclara. $Y$ enconformidad de lax cons. titucion quarenta y quatro paraqueno descaescala ladha Universidad encosa algun ir yseobserven y cuarden las demas aqui Anseras enfodo liempo inviolablemente. Pedimos y suplicamos con loda veneracion $y$ Rendimiento quecievemos al Rey nuestro Señor D. Carios Sequndo queDios Guarde muchos ytelices anos que siendole presentada por nuesIra parle esta fundacion laadmita debajo desu proteccion y Patrocinio Real en cuyas manos laponemos deello entodo yportodo pues Resulta enbien yprovecho desus vasallos se sirva de aprobarla despachando / las Reales Cedulas queen semojantes cassos seacos.

lumbran $y$ goce dha Universidad delas prehenminencias onores y previlegios que gozan las otras deEspaña ydeeslos Reyncs, y los quue enella segraduaren dela misma forma paraque con esso lengan premio los queenella estudiaren ylogren sus buenos deseos. enque Reciviremos la merced queesperamos dela grandezo, soberania $y$ liberal mano desu mageslad yparaquelodo losusudho aora yentodo ljempo se guarde ycumpla inviolablemente por nuestra parte, obligamos nuesiros vienes y Rentas, que de derecho devemos $y$ podemos obligar avidos $y$ por aver, yDamos poder cumplido alos jueces que demuestran causas puedan $y$ devan conocer contorme crel paraque aloque dho es nos executen compelan $y$ apremien porlodoslos medios y Remedios del derecho. $y$ como por senlencia difinitiva dejuez competente pasada enautoridad decosa juzgada; entestimonio deloqual alorgamos lapresenle carta quees techa enla dha ciudad de Guamanga ennuestro Palacio ycassas episcopales entrece dias delmes de jullio de mil y seiscienios ysetenta $\gamma$ siele años. Ylo firmo su señoria llustrisima aquien yo el presente escrivano dos lee que conozco siendo testigos el Bachiller Don Juan Rodriguez deMorillas previstero. Don Ysi- 
dro Pnchece, y den Miguel deSalazer elerigo Dianono presentes. Christobal Obispo de Giłamançs. Ante mi Francisco Blanco escrivano decavildo ypublico entre Renglones" de un mil rescs. Valga.

Fui Piesste., y en fee dello lo firmo $y$ feo

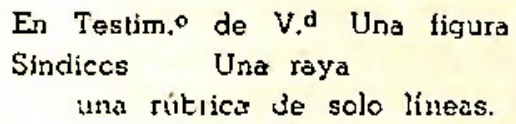

\author{
(fdo.) France Blanco \\ Escrivano de cavdo. y Pubọ / \\ (Una rubrica)
}

(i. 240 v.)

INOS el cavildo Justicia y Rejimiento desta ciu. ${ }^{d}$ de Guama, delas Provincias del Peru certificamos y damcs fee enquanto podemos ya lugar dedereche que franmisco Blanco dequien bajy nada y firmada laescriptura destaotra parte es escrivano desumagestad publico ycienuestro cavildo como senombra yautualmente Usa y exerse eldho oício yes avido ylenide por fiel legal ydecontianca yalas escripturas, autos yotros cualesqueer despachos queaniecl susodko anpasado ypasan como tal seles adado yda entera lee ycredito enjuicio y fuera dei yparaquedeello constelo firmamos afalta de escrivan: $\mathbf{s}$ publicos ni Peales porno haverlos enesta chaciudad de Guama, y mandamos sellar con el sello deella guess tha enela enveinte dias delmes de jullio de mil y seiscierros y setenia y siete años] orge Puccinelli Converso»

\author{
(ido. Don Fernando de \\ Molina yechaces \\ (una rulitica!
}

\author{
(fdo.) Don Felix ortiz \\ deespinoza \\ (una rubrica)
}

\author{
(ldo.) Don Gregorio de \\ Romani carrillo \\ (una rubrica)
}
(fdo.)Diego de Galindo (ido.) Don Anto de Berrecal (fdo.) Don Franco Hurtado y valenzuela (una subrices) , de Mendoza (una rubrica)

Una mancha Iedonda que parece ser de sello ilegible. 
Las iórmulas de los juranentos en latin que aparesen en astas Constituriones. cuya traducción insertamos a continuación, fueron hschas por w: colng. 1 do-pr Emilio Griraldo Caballero.

\section{Fórmula de dar Grado de Br. on Artoo}

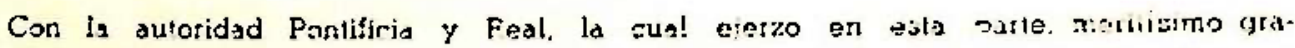
duando, te concedo e! Bjchillerato on ta ilustre Faculiad de Aries. $Y$ le dor iisercia para que fuedas stibi: a la cátedra $Y$ ahi interprelar a Aristóleles principe de los lllóscios, y por lo lanto puedes usar. oistrutar $y$ jozar de tedos los privilezios. excepciones $\theta$ inmunidades que posean $Y$ gozar lodos los distíngididos con grado semejanto en la Universided do Salamanca $y$ la de lima y n lasolras uniritsidades realn segín iss Eulas Apostólizas. para que de este modo te reconozcan este jrado, en tudas parses. lo cual sea para if un acentecimiente foliz en el nombra del Padie del Hijo $y$ del Espiritu Santo. Amen.

\section{Fómula de day Grado de Lixdo on Artes}

Con la autoriclad Pontitizia y Eeal qur. ejerze an osla parie. mrillisir:o Bachilier. te concedo e! zrado de Licenciado. para que cuando sees aprobudo por el Rector $y$ at Cinciller de Estudios de la Universidad. según las Bulos Apostólicus y Céaulas Reales. puedas ascender al grado de Maesiro en la ilusite Facultud de Átes. 7 le concedo totos los privilegios, inmunidades $y$ excepciones, las mismas que poseen $y$ gozan los que han alcanzado grado semejante en la Universidad de Salamanca y en ia de Ljma $y$ otras universidades teales, por tanto le reconozian $\in n$ lodas partes en $\epsilon$ ' nombre del Padre, dol Hijo y dal Espíritu Santo. Amsn.

\section{Forma de dar el Grado de Mro. en hrios "Jorge Puccinelli Converso»}

Con la sutoridad Pontíficia y Real, la cual ejerzo en esta parte. Licenciado merlígimo, le concedo el grado de Mrestro en la llustre Facultad de Artes por la inposición del "Birrete" y te concedo todos los privilegios, inmunidades y excepciones que poseen y gozan los que han alcanzado grado semejante on la Universidad de Salamanca $y$ en la de Lima $y$ en otras universidades reales, er el nombre del Padre, del Hijo $Y$ del Espirilu Santo. Amén.

\section{Fórmula de dar el Grado de Br. en Thoología}

Con la auloridad Pontilicia y Real que ejerzo en esta parte, meritisimo Laliroando. In concedo el grado de Bachiller en la Facultad de Sagrada Teología. Y to doy "Licencia" para que puedas subir a la cálédra y ahi interpretar al Maestro de las Senteurias, por tanto puedes usar, distrutar y çozar de lodos los privilegios $y$ excepciones que poseen Y gozan todos los distinguidos con grado semejante en la Universidad de Sa!amanca $y$ la de Lima $\gamma$ otras universidades reales, según las Bulas Apostólicas y las Cólulas Reales., para que de este modo reconozcan en todas partes tu grado, todo lo cua! sea para ti un acontecimiento teliz. en el nombre del Padre, del Hijo y del Espiritu Santo. Amen. 
Con la autoridad Pontificia y Real que ejerzo en esta parte, meritisimo Bachiller, te concedo el yrado de Licenciado para que cuando seas aprobado por el Recior y Can ciller de Estudios de la Universidad, según las Bulas Apostólicas y las Céduias Reales, puedars ascender al grado de Doctor $y$ te concedo todos los privilegios e inmunidades que poseen y gozan los que han aleanzado grado semejante en la Universidad de Salamanca y en la de Lima y en otras universidades reales, para que de este modo reconozcan tu grado en todrs parles, en el nombre del Padre, del Hijo y del Espirtu Santo. Amen.

\section{Fórmula del Grado de Dr. en Theología}

Con là àtoridad Pontificia y Real que ejerzo en esta parte, meritísimo l.icenciado, te concedo el grado de Doctor en la Facultad de Sagrada Teología y por la imposición de este "Birrete", le concedo todos los privilegios, inmunidades y excepciones que poseen y gozan los que han alcanzado grado semejante en la Universidad de salamanca y en la de Lima y en otras universidades reales, en el nombre del Padre, del Hijo y del Espíritu Santo. Amen.

\section{Fórmula para el Juramento de los Graduados de Doctor y para los que deseen} incorporarse a la Universidad

Yo N. juro por estos Santos Evangelios de Dios que realmente toco, que en los asunics reefrentes à la Lniversidad con hechos ypalabras, prestaré favor y aỹuda fielmente y guardaré diligentemente todo lo que las Bulas Apostólicas y Cédulas Reales de esta Universidad, contienen, en cuanto respecta a la facultad de aprobar para dar grados y en lo que se refiere al Ilustrísimo Señor Obispo de Huamanga o al Capítulo "Sede Vacante" de esta Iglesia Catedral, para conferir los mismos grados y que tiene su perfecto y estricto cumplimiento; asi mismo, en cuanto al llamado del Rector de la predicha Universidad, acudiré tantas veces cuantas fuere requerido; y en el Consejo, no iré contra las Constituciones y Estatutos de la predicha Universidad, y así Dios me ayude por estos Santos Evangelios.

(f. 237)

\section{Fórmula del Juramento para defender la Purísima Concepción de la Virgen Santísima a que deben emitir los Bachilleres y Doctores en Theología y Licenciados en Filosofía}

Yo N... Por estos cuatro Santos Evangelios que realmente toco, devotamunte juro y prometo a Dios Umnipotente y al hijo de la Virgen Santísima, y a la misma i, íadre de Dios que es Madre de la Sabiduría, Maestra de las gentes y disciplina de las costum- 


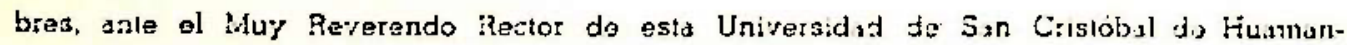

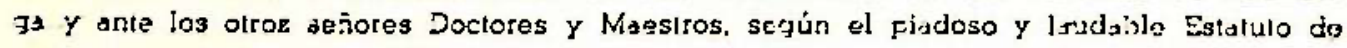
osta Universjatad, el cual deseo tue sea estable $y$ perpeluo, $Y$ hatrá de profisarlo. ensoñarlo $y$ defendes!c en todas parles. $y$ jamás procederé de olra manera con palabras y po: escrito, bajo ningún pretexto. En cuanto a aquella natural concepción do la Virgan Santigima en el primer instante de su vida. está absolutamente exenta de tods mankha original. por io tanto en ningún momento del tiompo. le afeclis el primer pecacis de nuostros primezos padreg, lo cual se ciebe tener por manciato de la iqlesia Catálica y de los Santísjmos Pontítizes; en cuanlo a mi toca. de todo corazón con!jeso y creo. para gloris do Dics y de la Virgen Madre. Esplendor de la Sabiduria. Ornamento de esla Academia. y espero slcanzar la salvación de mi alma.

\section{Prolosión de Fé}

Yo... N... con fó tirme, cree $y$ profeso lojas $Y$ cada una de las vordirden quo eslán contenidag en el Símbolo de la Fó, el cual usa la Santa lgiesía Romana a gavar: creo en un solo Dios Omnipolente. creador del Cielo $\gamma$ de la tierta, de lodas lás cosas visibles e invisibles $y$ en un solo Señor Jesueristo, hijo Unígénito de Dios. $y$ nacido del Padre antes de lados los siglos; Dios de Dios, Luz de Luz, Dios verdadoro de Dios verdadero. Engendrado, no creado; consubstancial al Padre por quien han sidu creadas lodas las cosas, que por nosolros los hombres y para nuesira salvación, bajó de los cielos y se encarnó en Maria Virgen. por obra del Espiritu Sonto, se hizo hicmbre, y bajo el poder de Poncio Pilato, padeció, luó cruecificado $\ddot{z}$ luego sopultado. Rosucitó al tercer dia, según las Escrituras, subió al cielo: está sentado a la diestra de Dios Pix dre $y$ otra vez ha de venir, congloria. a fuzgar a los vivos y a los muerios y su reino no tendrá in. Creo en el Espítitu Santo. Soñory yiviticador que piocede stel Padro y del Hijo, al cual es adorado. glorificado juntomenle con el Padre $y$ el liijo, que lia. bló por los pró́etas. Creo en la Iglesia que es Una. Santa, Católica y Aposiólica. Confieso que hay un colo Bautismo para el perdón de los pecados, $y$ espero la resurrección de los mugrtos y la vida del siglo venidero. Amen.- Firmemento ordmito y abiazo las tradiciones Apostólicas y Eciestísticas, las Coristijuciones $y$ demás rosas qus ahserva la misma Iglesia; asi mismc, admio las Sagradas Escrituras según el sentido que en la Santa Madre Itjlesia ba lenicio y tiene, a quien corresponde juzyar en isurito a su verdadero sentido $y$ en cuanlo a su interprelación $y$ por tanto jamás admitiré é interpretaré sino serjún el sentido de los Sanios Padres. Declaro también que verdadera y propiamente, son siete los saramenlos de la Nueva Ley, instituides nara la salvación del género nurrano son nazesarios para tołos, y son, a saber: Baystismo, Confirmación. Eucaristía, Penilencie. Extremaunzión, Orden y Matrimonio. Esics contieren Gricia; Io los cuales el Bautismo, la Conílrnación y el Orden, una vez recibidos no se pueden repetir sin incurir en sacrilogio; también aceplo los ritos aprobados por la Iglesia Carólica para la solemne administracion de todos los predichos Sacramsitios. y admito y abrazo lodas aquello que ha sido definido en el Sacrosanio Símbolo Tridentino en lo que se refiere al pecado original y a la iustificeción. Igualmente declaro zue en la Misa se ofrece a Dios verdadero, y propiamente es un sacrificio propicintorio por los viros y por los difuntos; asi mismo daclaro que en el Sentisimo Sacramento de la Euraristi., estí ver- 
dera y tealmente el Cuerpo y Sangre. juntamente con el alma y divinidar de Nuestro Señor jesucristo y se hace la conversión de toda la sustzncia del yino en su sangre. la cual conversión, la Iglesia Católica llamó iransubstanciación. Contieso además, que bajo la especie de pan solamente, todo e integro verdaderamente, está el Sacramento. Constantemente tengo, que las almas relenidas en el Purgatorio, son auxiliadas con los sufragios de los fieles; irsi mismo atirmo que se debe venerar a los Sanics que ieinan con Cristo, a quienes se les dece invocar $y$ ellos ofrecen a Dios oracionas por nosotrcs, cuyas reliquias doben do ser veneradas; asi mismo las imágenes de Cristo y da la siem. pre Virgen Maria y jo los oltos santos. deben tenerse y conservarse y se les debo tribular el debido honor y veneración: afirmo que da iglesia ha recibido de Cristo el po. (1. 238) der de dar indulgencias para el uso del pueblo cristiano, principalmento para su saivación. Reconozco que la Sunta Iglesia Católica Apostólica y Romena es Madre y Muestra de lodas las Iglesias y solemnemente prometo verdadera obediencla al Romano Fontífico San Pedro, Princtro de los Apóstoles y sucesor y Vicario de Jesucristo y juro observar lodas las denıás zoses. Asi mismo. declaro $y$ acepto. sin poner duda, leda aquello que han propuesto. definito y declarado, los Sagrados Canones, les Concilios Ecimménicos y principalmente el Sagrado Sinodo Tridentino. Así mismo. 1odo lo que de cualquier Inodo es contrario y herátice y que es condenado. rechazado y analematizado por lax Iglesia yo también, condenr. rechazc $y$ analematizo: esta es la verdadera Fé Católica. f:rera de la cual nadie puede salvarse, la cual ahora libremenle. declaro y engo como verdadera. la misma que integra e inviolable, hasta el fin de mi vida. con ánimo cons. tanie (con la aryuda de Dios). prometo solemnemente guardar y confesar, asi como por mis súbditos o por aquellos cuyo cuidade me respecta por mi carçc, prectraré hacer cumplir; yo... prometo solemnemente. ofresco y juro, $y$ asi Dics me ayude por esios santos Evangelios cie Dios.

\section{Biblioteca de Letras "Jorge Puccinelli Converso"}




\section{CONSTITUCIONES AÑADTAS DE LA UNIVERSIDAD DE SAN CRISTOBAI, DE HUAMINTGA, DADAS FOR EI EXCELENTISIMO SEÑOR OBISPO DE LA CIJDAD DE HUAMANGA, DOCTOR DON DIEGO LADRON DE GUEVPFA}

Trascripción de una copia fotostática pzoporcionada por el Reverendo padre Rubén Vargas Ugarte, quién en su viaje a Europe, pudo adquirirla, en los Archivos de Seville.

"Den Ysidro Pacheco de Guzmen Secretario de la Real Universidad de San Xptobal fnndiada en esta Ciudad cie Guamanga. Certifico y doy Verdadero lestimonio en quimio puedo y á hugar, en derechö, como enVeintcy ocho del Mes de Febrero de mill y sotecientes y quatro años el Yllino-S. D.or- Disgo Ladron de Guevara, del Consejo de su

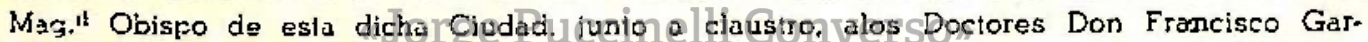
cia de Loaysa Dean de sta. S. li Yglesia Cathedral = Don Andres de Munibe chanciller de esta Universidad Probiscr y Vicaric General deste Obpdo=- Don Eusebio de Medina y Risso Cura y Vicario de la Doctrina de Cangallo Provincia de Vilcas Guaman Don Juan delaVega y Quiros, $y$ Don Pedro de Romani y Carrillo Procurador de esta dicho R. Universidad y Abogado dela| R.' Audiencia delos Reyes, para nombrar en el los mtnistros, que falltaban necesarios y que acostumbran lener las demas Universidades| Gene rales, y hacer saber en dho clausiro un auto, que 70 el presente se|cretario ley en alla voz de verbo ad Verbum, cuyo tenor sacado a la lejirn= es como sigue $\rightarrow$ )

Nos el D."r Don Diego Ladron de Guevara por la gracia de Dios! y de la Santa Sede Aposiolica Obpo de esta Sanla Yglesia Calthedral de Guamanga y del Consejo de su Mag."l att.t Por guanto el Y11.mu S.: D.ar Don Xplobal de Castilla Y Zamora obispo q. Lue de dha Santa Yglesia Y Arzobispo dela Flata, fundo de sus bienes proprios une Universided de estudios Generales| para esta Ciudad, la qual confirmo La Santidad del Señor| Ynosencio Undecimo por Bulla de Veinte de Diciembre del mill seiscientos y ochenta $y$ dos años, y Su Mag.l Catholica y El señor Carlos Segundo recivio debajo de su R.l Patronatol por cedula su fecha entreintay uno de Diciembre de mill $y \mid$ seiscientos y ochenla años; y no á podido tener Cumplim.to| a esla los presenles tiempos, por por la contradiccion que formól la R.' Universidad de San Marcos dela Ciu. d delos Reyes| en el Superior Govierno de estos Reynos, pretendiendo em=-|barazar el Passe de 
dina. R.' Cedula, sin embargo de la| qual se sirvió su ex." el S.r Virrey Conde dela Monclobal con volo consultivo del R.1 Acuerdo concederle segun consta,! del exezutorial. que está puesto en el Archivo de esta R.l Universidad, en cuya Vista emos procedtdo a entablar $y$ poner enpractica dha. Universidad, $y$ yor que para su mayor aumento $y$ conserbacion emos reconocido ser necessarias! alọuns nuebas constituciones, y declaraciones sobre las an!tiguas de las quales ay alzunas, que con el transcurso del tijem. po se a dificuliado su observancia, usando de la facultadi de fundan de dicha Universidad. por la aqrogación de las Renftas, que tenemos hecha, y restauracion de las fincas affectasi a dicha R.' Universidad, que tenia cassi del todo arruyna=|das el tiempo, con que se á dispuesto dotar las Cathedras. com=-1mo se dirá en la Constitucion que sobre esio haliere y con consulis del claust:o tenen:os dispuestas lirs siguientes para que se obserben en luerza de contrato en el interino| que se suplica a su Mag." se sirva de aprobarlas $y$ conírmarlas.

\section{Conslituclon 1 a}

15 For quanio anla Constitucion diez $y$ seis este prebenido quel de los redites de las cassas Episcopales se paguen las cathe=-ldras, en cuyas rentas se dotäron conforme la cotislitucion| diez y siete, el qual dho. Palacio Episcopal se halla alpresentel y de muchos años destaparte, casi arruynado. por no haberl querido avilarle los señores abpos. ni haber habido peson=-lna que acudase desu reparación y dehemos do. clarar, que aunlque se bolbiera a reedificar, no habrapersona que quiera halbitarle con el cargo, delos arrendamientos, por causa de lal mala situación de dhas, cassas: emos determinado hacerl en ellos las Escuelas de dha. R.l Universidad enla parte q.' hoceironte enveinte $y$ una baras. $y$ con el índo do cinquental dojando la Cassa pequeña, que está de espaldas de esta princicipal=l para renta de dhas. Cathedras, sogun se dirá mas | largamente en la Constituciom qūe sobre esto trate, y paral que se labren los Generales, capillar, secretaria y demas piezas| necesgarias tenemos concierto con el Maestro Alari=|fer de tres milt setecienlos y cinquenta pesos, para cuya sa=|tis. faccion an contribuydo muchos de los vecinos de esta| Clud y los Curas del Obpdo y assi lo declaramos en sta| Constitucion de consulta y parecer del Claustro para que en| todo liempo conste el estado en que hallamos dichas cassas| segun parece da la tasacion jurada que hicieron los Maes=-itros Alarifes que queda en el Archivo de la Universidad.

\section{Conalituciones $2^{a}$ delas Rentas y Doltacion do Calhedras}

2a Declaramos que para dotacion y rentas de las Cathedras| de Prima, y Visperas de Theologia de Theologia Moral quel nuebamente emos fundado, y la de Artes tenemos nobecientos| pesos de reditos en cada un año segun consta de las Scrlptulras que quedan en el Archivo de esta R..$^{1}$ Universidad $=$ y son| en la forma siguiente= Ciento y veinte $y$ cinco pesos sobre la Cas/sapequeña, que está a espaldas de dhas escuelas, = cientoy olchentapesos, que rentan las tiendas de la Casa principal del dhas escuelas - Cinquenta pesos sobre la cassa de Juan Mar|tinez scrivano, en la calie, que sube del Combento de Santo Dolmingo a las cassas de Don Andres de Berracal las quales tres $=\mid$ partidas, hacen trecientos $y$ cinquenta $y$ cinco pesos, que son| los 


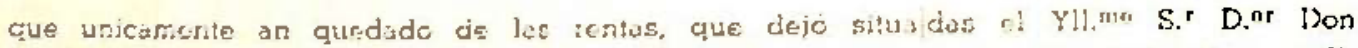
Xptetal de Caslilla y Zamora $=$ Y los quel fircs jualudo con nuestra industria $Y$ soli citud sen cono se:=| siguen = trecierics pesos sobre la hacionda de Pincos que; inslulu7ó Y luncio el Liz.'to Don Fernando de Pro Leon cura dei la Docirina de Guancaramlacinquenla pesos socre la ha ceiendo le Cochabamba Docirina de Ticllas. que dolo para renta. Dor soseph Gilindo Parccal- Cincuenta pescs! scbre la hacienda de Yucay y Doclrina de Quinoa, que constituyó fcr rentá de dhas Cathedras Don Esteban de Maisondo A.lcalde Provincial= Cienpesos scive las cassas do Doña Maria hornani. Jue hacen esquina a la plaza mayorl de esta Ciul = Cinquenta pesos sobre la hacienda de Chinchero! Cinquenta pesce sabre el Yusuy re Acciapa $y$ hacienda Je AyalAyaguarcu. $Y$ juntos dichas partidas conlos que guardaron| liquidas de la fundarion inportan novecisnles $\gamma$ cinquental $y$ cinco pescs. $\gamma$ el excesso de los seircientcs pesos de renta en cada un año le emes solicilado delos vecinos de la Villa de Guan|cabalica y de este Cin." $y$ de las diches nobecientos $y$ cinçucnta $y$ cinco pescs dotamos las dhas Celhedras en la forma siguientol

A. la iClinedía de Prima en Titeología señeternos de ren=tla en cada un año tre cientos pesos = a la de Visteras doscientos a la de Moral doscienlos= A la de Artes doscientos y los cin=equenta $y$ cinco pesos restantes, para integrar dhas rentas en cassol que hubiere alguna quiebra, o para gasles de las cobranzas de dhasl rentas de la tiniversidad. $y$ esperamcs con el tiempe foder adelantarl mas Calhedras, o que los se. ñores vivcs sucessores lo excuten=

\section{Constitucion $3^{c}$ de las fiestas que}

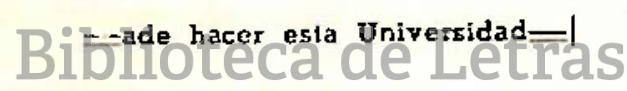

\section{"Jorge Puccinelli Converso"}

3o Por quanto en la Costilucion pirineta esía mandado que todos| los años se haga una fiesta al Sanlo S. Xptobal al tivular de dha Uni|bercidad, y otra a Santa Colhalina Martir en la forma $\mathrm{g}$. ello sel prebiene; ahora nosotros por el derecho que tenemos en dha Uni=jversidad de fundador $y$ de consula y parecer del Claustro man|damos que assi mismo haga la Universidard todos los años una fiesta con su Missa Canlada y Sermon al Glorioso San Diego en el conbenlio de San Francisco ensuproprio dia; - Monaslerio del Carmen en el Aitar de Senta Liberata, donde esla el bulto del Sanlo= Y otraj en el Conbento de Santo Domingo el dia del Glorioso Doctor Santo Tho!mas con assislencia del Claustro en ambas funciones=- $\mathrm{Y}$ por quel todos los graduados en esta R.I Universidad hasen yhande haser eljuramento de defender la inmaculada Concepcion de Maria S.S.| para que al mismo tiempo solemnice dha Universidad tan alto mis=-|terio, y reciva su mayor incremento el conjuro delan soberana, yl sabia Señora, manda. mos que todos los años en el octavario que sel celebra a esie misterio en nra Yglesia Cathedral, tenga a su cargol la celebracion de uno de los dias esta R. I Universidad.

Y para este dia y demas festividades a que quisjere assistir| en nra. Yglesia Cathedral dha. Universidad con imsignias o sin ellas! le señalamos por assiento en que so pongan las hancas el coraleral| izquierdo del coro, que corre clesde la grada de el hasta el primerl arco dela nabe 


\section{$-225-$ \\ Constitucion $4^{\alpha}$ de las propinas y costos de los grados}

4⿳亠口冋 Aun jue desde la Constitucion Veinte y cinco hasta la treinta y| ocho, está dada la forma del deposito, cue ande hacerlos gra|duandos, conforme al grado, que pretendieren y prebenida las' propinas, que sean de dar habiendo parecido por la Variedad de losi tiempos, que en al consulta de dho Claustro mandamos se ob|serbe en adelante la forma g. aqui sepone dela cual se dará| al Thesorero, y otro al Secretario, para que segun su disposicion admitan, los depositos, y no enotra

\section{Grado de B.: en Ärtes}

Depositará el graduando dies y ocho pesos $q^{\prime \prime}$ seande repartir en| la forma siguiente A la Caxa dos pesos= A la Capilla un pesol Al S.r Obpo quando da el grado dos pesos = Al Rector dos p. ${ }^{\text {q }}$ Al Chanciller quando confiere el grado un peso= Al Padrinol dos pesns= Alos tres arguyentes acaUno un peso= Al Secretariol dos Bedeles mayor y menor $y$ thesorero acada uno un pesol. Lo demas que sobrare seade repartir entrelos Maestros en artes y Doctores|en Theologia, que asistieren, y se advierte que los dos pesos del Rector por nol haberle alpresente se anderepartir como tambien elpeso del Chanciller quan|do no assistiere, o quando diere el grado, porque entonces percibirá los dos p.8| de graduante= tambien se advierte, que en assistiendo, pocos Doctores, o Maestros,| se á de hacer la reparticion de suerte que no lleben mas de un peso cada uno y lol que sobrare se aplica ala Caxa ylo mismo se hará en los demas grados de Bachi|ller en otras facultades

\section{Grado de $\mathrm{B}^{r}$ en Theologia}

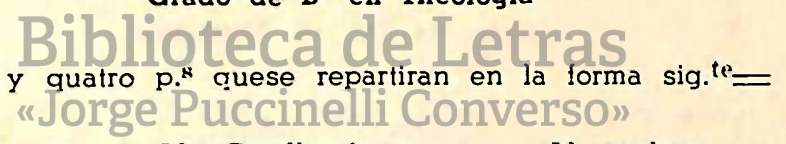

Depositará veinte y quatro p. quese repartiran en la forma sig. ${ }^{\text {" }}=$

A la Caxa quatro pesos = Ala Capilla dos pesos= Al graduante quees| su Yll.ma dos pesos=Al Rector dos pesos=Al Chanciller quando as/sistiere un peso= Al Padrino dos pesos: a los tres examinadores| acada uno un peso= Al Secretario dos pesos Bedeles y Thesorero al cada uno un peso=y los tres pesos que sobran seanderepartir entre los| Doctores en Theologia, que assistieren y si sobrare para la Caxa| como se dijo en el grado de Bachiller en artes

\section{=Grado de Liz.'lo en Artes}

Se depositará lo que importaren las partidas sig.ter = A la Caxal catorcepesos= a la Capilla ocho= Al S.r Obpo. doce= Al Rector| doce=Al Decano, o Padrino diez - Al Chanciller ocho p.s/= A los examinadores, que ande ser cinco de los Maesiros o Doctores| en Theologia acada uno ocho pesos, los quales seande repartir en|tre los dhos examinadores en esta forma = el dia del acto publicol sea de dar arcada uno atres pesos, el dia de tis puntos otros tres $\mathrm{p} . \mathrm{s} \mid$ y el dia de la leccion secreta dos pesos, y un peso mas en el dia q.| se confiere el grado, y en la misma forma sempartiran las prolpinas del S.r| Obpo. Rector Chanciller Padrino Secretario y Bedeles=l 


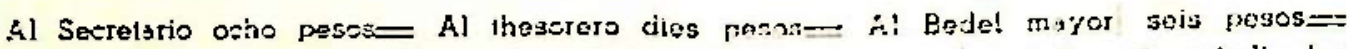

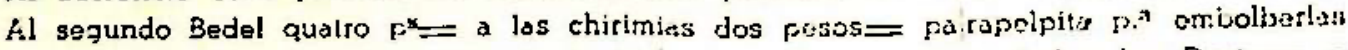
propinas. $Y$ celos para la noche de la lec;-cion dos peso3= alcdos los Doctores $Y$ meestros se les $\mathrm{d}$ u un peso eli dia que se continte ol grado. $\gamma$ en este rumero entrmi el Sr Obpo R.nr: Chanziller $y$ examinadores

\section{Grado de Maestro}

Se deopsitará lo siquenté A la Cara Veinle pesos= a la Capills ratorce p.* $=$ A! S.r Obpo. dece p." Al R.ur dece pal Al Chanciller coho pezon= A.l Padrino diez. pesos= Al Secretariol diez pesos= Al Thesorero ocho pesos= Al Bedel maryor ocho p" $y$ ! al otro Bedel seis pescr acada uno de los fíaestros a orho pesos== alos Doctcres de olra facultad squatro pesos= chirinias $Y$ ataha=-liles quatro pesos papelpita $Y$ Cixita dos fesos

\section{Grado de Lis. on en Theologia}

A la Caxa veinte $y$ quatro pesos= A la Capilla diez Y ocho= Al S.r Obpol diez $y$ seis = Al Rector diez Y seis= Al Dezano. O Padrino calorce phe Al Chancillnr docep* = Al Secrelario calorce $p^{n}=$ Al Thesorero ocho pesos=! A! Bede! Mayor ocho p." = a! otro Bedil seis pesos-- alos cínco exa|minadores que ande ser los Doztoros mas antiguos acada uno dolce pesos repartidos en las tres funciones, como ya se dijo=... A cajal uno de los Doctores. en que entran los demis examinadores exceplo.l los ministros= A las chirimias un peso_e para parpal plla y belas dos p."

\section{BiGradodeepranthoologiatras}

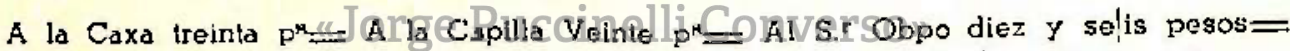
Al Rector diez y seis $\mathrm{p}^{*}=$ Al Chanciller doce $\mathrm{p}^{*}=$ Al Padrinol o Decano Catorce $p^{p}=$ Al Secretario calorce $p^{2}=$ Al Thesorero diez pesos-al Al Bedel mayor diez posos= Al mener ocho- chirimiers $y$ atalbales quatro $\mathrm{p}^{*}=$ papel pita $\mathrm{y}$ Caxita en $\mathrm{q}$. ac !leban las propinas dos pyl A cadá uno de los Doctores y Theología los ocho pesos do Propina $y$ | guatro de colacion $y$ guantos= A los Maestros a seis pesos aca= dia uno entrando los guantes $y$ colacion, $y$ es adbertencia $\alpha$. q. grado la propina del graduante le toca all chanciller $y$ al S.r Obpo. so le dá lo $ণ$. lo locaba a dho chanciller.

\section{Constitucion $5^{\alpha}$ del Oticio de Thesorero}

50 Por quanto, es necesario que aya una persona abonada en sta R.!! Univorsidad. que sea del cuerpo del Claustro, $y$ de fuera en cuyo po/der entran los depositos, y lo que perteneciere a las arcas y Capillal y que asi mismo cuyde de cobrar las rentas do dha Univiersidad! para pagar los Cathedraticos, lo qual no se prebino en las Constituciones|, erigimos $y$ criamos este officio, $y$ tenemos ya nombradal persona de satisfaccion para el Dejando facultad al Claustrof para que siempre que $v$ sare dicho officio pueda nombrar perisona que lo ejersa dando fianzas correspondientes y a de ser obliga|do 
a cobrar las rentas, for cuyo cargo le señalamos el tres for ciento de| lo que cobrare y propina la que le esta consignada en los grados|.

\section{Constitucion $6{ }^{\circ}$ del tiempo en q.c seande}

\section{leer las Cathedras $=$}

69 Para a. los cursantes de estas Escuelas puedan tener algun tiempol desembarazados, en q. puedan estudiar las materias que hubieren| escrito en cada año, mandamos. que las iecciones y cursos solo duren| desda el Lunes inmediato a la Dominica in Albis, hasta el dial en que se cumplieren seis messes; con advertencia de que sin este | liempo, no pudiere el Cathedratico de Artes acabar la material de aquel año, prosi. ga hasta Navidad, y asi mismo los cathedra|ticos de Theologia proseguiran leyendo, acabados los seis meses, tres meses mas para que lo quisieren ganar cursillo que junto con otro| hace curso entero, y aunque por las Constituciones quince, diez y sieịte y veinte y una esta determinado el iempo delos cursos manda|mos que aora no se cbserben asla informar a su Mag."

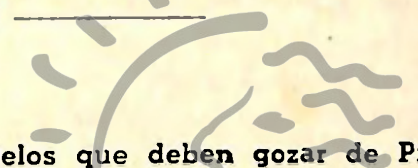

\section{Const. "n 7ִ̣ acerca delos que deben gozar de Privi|legio en los Grados}

7ạ Por quanto se halla prebenido en las Constituciones de esta Univer/sidad que los Collegiales de este Collegio, seminario gocen el terciol menos en sus grados, mandamos gocen del mismo Prikilegio los hi $=$ jos lexitimos de los Doctores y Maestros de esta Universidad

\section{Biblioteca de Letras "Jorge Puccinoullidonverso"}

8? $\mathrm{Y}$ por que en todas las Unibersidades, congregaciones y Collegios sel hacen algunos sufragios, por los difuntos de aquel gremio, madalmos $y$ en el Mes de No biembre se hagan todos los años unas honrras| con missa Cantada y Vigilia por los graduados Difuntos

\section{Const.on gạ acerca de los examinadores}

9ạ En todos los grados mayores ande assistir siete examinadores y| declaramos, que en estos no se deben contar el S.r Obpo., ni el Chanciller del los quales el primero debe ser siempre examinador șupernumerario y ell segundo siendo graduado y no de otra suerte = para los grados de Maestros| an de ser los siete M.ros y a falta de estos Doctores en Theologia, pero en graldos de Theologia nunca pueden ser examinadores los Maestros ni Doctores| en Medicina.

Las quales constituciones se ayan todas de obserbar en fuerza dé contrato, entretanto que su Mag.' se sirva confirmarlas, y sin| que en el entretanto, pueda el Claustro derogarlas, ni introlducir obras en algun modo contrarias aestas, ni a las que su Ma." 
tieno ya aprobadas, pues no hay facuilad en cino. Cisusirji pars poderlo hucar, no siondo alprincipio dela fundacion, como las que al presante se an hecho. $Y$ lo firmo su señoria Yll.m con $=$ todos los del Clausiro. de que dey jee= DIEGO Obpo. de Guarnanga, D.n D.n Francisco Gatcia de Louiza = D."r Don Andros de Munilbe= Doctor Don Eusesio de Medina y Risco= D.ur Don Juan de la V4fos Y Quiroz= Doctor Don Pedro de Romani $y$ | Carrillo.

Segun que lo referido consta $y$ parece del Litro de Claustros quej sia ami cargo. $y$ para que conste a donde conbenga doy olj prescole de orden $y$ mandado del Claustro de Dactores de esta Real Unifversiajad de Guaranga en veinle dias del mes de Agosto do mill $Y$ eetecientos $y$ quatro años

\author{
(fdo.) Don Ysidro Pacheco) \\ de Guzman \$.rl" \\ iuna rúbrizs\}
}

Noz log ess, num que aqui firmamos y stqnamos' Damos tes en quanto pedomos quo Den Ysidro Pacieso, do Guzman de quion persese firmado el Ynstrumento de|Aribu os. Sectetario de la R.' Universidad de E." Sanchris|iobal de esta Ciudad, de Guamanga $Y$ a sus semexantes se! les adado y da entera tao y crejitos en hicio y tueradell y paraque deello conste donde conbenga, Dimos Lapresente en la dha Ciu' de Guamanga del

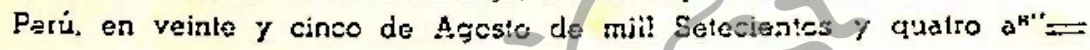

Ante $\mathrm{mi}$

En teste de la Verdaci

(Ho. Fran"i (Sarv) de Urtesga

Escrivo do su Mag."

(una rubrica)
Ev testi:nonio de la Verdad ('jo.) Liquel de Alvites Secro de su Mag.'I (una rubrica) Biblioteca deifdo En testimonio de Verbano de los Roven

"Jorge Puccinelli Convers do su Maq."I

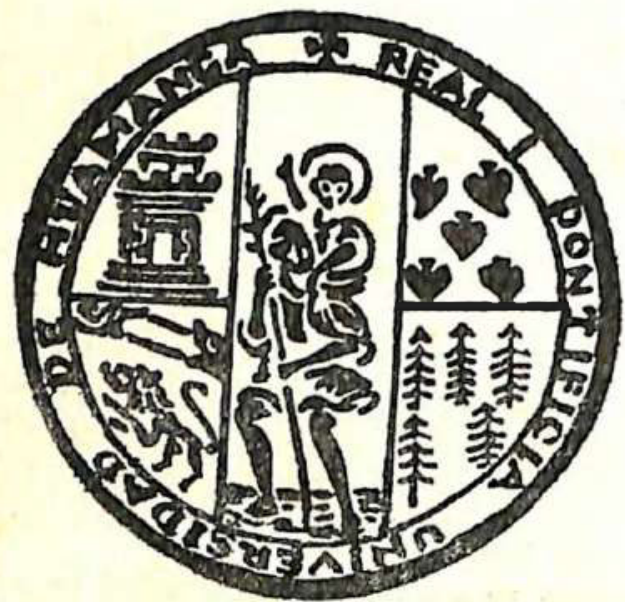

Sello de la Universidad do San Cristóbal de AYacucho 